\title{
PRELIMINARY LONG-TERM STABILITY CRITERIA FOR COMPRESSED AIR ENERGY STORAGE CAVERNS IN SALT DOMES
}

\author{
INSTITUTE FOR ENVIRONMENTAL STUDIES \\ LOUISIANA STATE UNIVERSITY \\ BATON ROUGE, LOUISIANA
}

prepared for

Battelle

Pacific Northwest Laboratories

Richland, Washington

Special Agreement B-54804-A-L

Prime Contract EY-76-C-06-1830

August 1978 
33679000532137

PRELIMINARY LONG-TERM STABILITY CRITERIA FOR COMPRESSED AIR ENERGY STORAGE CAVERNS IN SALT DOMES

\author{
by \\ R. L. Thoms \\ J. D. Martinez \\ INSTITUTE FOR ENVIRONMENTAL STUDIES \\ LOUISIANA STATE UNIVERSITY \\ BATON ROUGE, LOUISIANA
}

\author{
prepared for \\ Battelle \\ Pacific Northwest Laboratories \\ Richland, Washington
}

Special Agreement B-54804-A-L

Prime Contract EY-76-C-06-1830

August 1978 
PRELIMINARY LONG-TERM STABILITY CRITERIA FOR

COMPRESSED AIR ENERGY STORAGE CAVERNS IN SALT DOMES

\section{Contents}

Section

Page

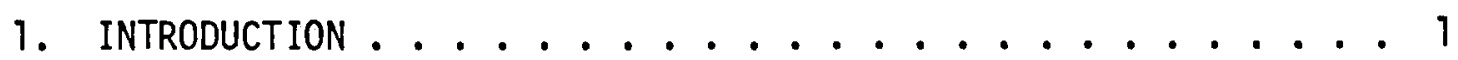

1.1. objective ................ 2

1.2. Significance ............... 3

1.3. Scope of Study . . . . . . . . . . . . 3

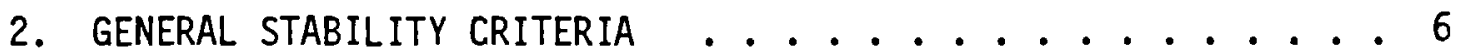

2.1. Summary of Factors Affecting Cavern Stability .... . 6

2.2. Principal General Stability Criteria . . . . . . 6

3. STATE OF THE ART SURVEY; PRINCIPAL FINDINGS AND

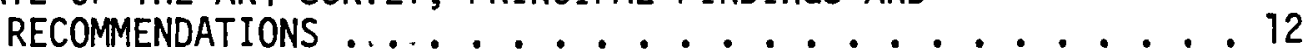

3.1. Principal Findings .............. 12

3.2. Principal Recommendations .......... 15

4. FACTORS AFFECTING CAVERN STABILITY IN SALT DOMES ..... 18

4.7. General ................. 18

4.2. Site-Specific Dome Utilization History . . . . . . . 19

4.3. Geologic Features of Salt Domes . . . . . . . . . 21

4.4. Geometrical Configuration .......... . 23

4.5. Material Properties . . . . . . . . . . 29

4.6. Loading Parameters . . . . . . . . . . . 50

5. DEVELOPMENT OF SITE-SPECIFIC STABILITY CRITERIA . . . . . 54

5.1. Testing Methods for Data Gathering . . . . . . . . 54

5.2. Development of Criteria in Stages ......... . 56 
6. IMPLEMENTATION OF STABILITY CRITERIA FOR CAES CAVERNS . . . 64 6.1. Phase (1): Site Selection .......... 64 6.2. Phase (2): Cavern System Design .......... 65 6.3. Phase (3): Facility Operations .......... 67 6.4. Schematics for Stability Criteria Implementation . . . 69

7. COMPARISON OF COMPENSATED VERSUS NONCOMPENSATED CAVERNS • 73 7.1. General ................ 73

7.2. Relative Effects on Cavern Stability . . . . . . 73

8. CONCLUSION . . . . . . . . . . . . . . . . 77

8.1. Summary ................... . 77

8.2. Concluding Remarks . . . . . . . . . . 77

9. REFERENCES .................... 78 


\section{LIST OF FIGURES}

Title

Page

1.3-1. Salt Deposits of the United States ........ 5

4.4-1. Typical Dimensions Specifying Confiyuration ..... 25

4.4-2. Horizontal Dimensions of CAES Cavern System . . . . 28

4.5-1. General Response of Rock Salt ........... 34

4.5-2. Typical Stress Strain Curves for Salt Rock . . . . . 37

4.5-3. Strength of Salt Rock at $2 \%$ Deformation . . . . . . 39

4.5-4. Strength of Salt Rock at 10\% Deformation . . . . . . 40

4.5-5. Strength of Salt Rock at 20\% Deformation ....... 41

4.5-6. In-Situ Representation by Triaxial Extension Test ... 44

4.5-7. Creep Closure Effect in Salt Mine ........ 46

4.5-8. Creep Rupture Effect at Corner of Salt Pillar . . . . 46

4.5-9. Triaxial Extension Creep Curves .......... 47

4.5-10. Uniaxial Compression Creep Curves . . . . . . 48

5.2-1. Stage 1: Laboratory-Bench Scale Testing ....... 57

5.2-2. Stage 2: Pilot CAES Cavern Monitoring . . . . . 58

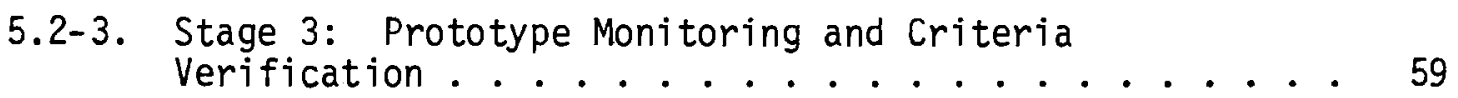

5.2-4. Components of a Dome Monitoring System . . . . . . 62

5.2-5. Interaction of Efforts in Data Interpretation ... 63

6.3-1. Weekly Cycle of Pressure and Temperature in CAES Cavern ............... 68

6.4-1. Phase 1: Implementation of Stability Criteria in Site Selection ........... 70

6.4-2. Phase 2: Implementation of Stability Criteria in Cavern System Design ............ 71

6.4-3. Phase 3: Implementation of Stability Criteria for Operating Program .......... 


\section{TABLES}

Title Page

2.1-1. General Factors Affecting Long-Term Stability of CAES Caverns in Salt Domes........... 6

3.2-1. Topics For Additional Study Relative to Long-Term Stability of CAES Caverns in Salt Domes ........ 17

7.2-1. Relative Effects for Compensated versus Noncompensated CAES Caverns in Salt Domes .......... 7 . . 


\section{INTRODUCTION}

Compressed air energy storage (CAES) has been implemented in west Germany and possesses the potential for being of significant utility in the USA $(6,25,49,51,78,86,90)$. Projections of a desirable useful "life" for CAES facilities include a time period of around 35 years of cyclic operation. Thus the air storage caverns, which are an essential and integral component of a CAES plant, should be designed and operated so as to perform satisfactorily over the intended life of the overall facility. It follows that the long-term "stability" of air storage caverns must be considered as a primary concern in projecting the satisfactory operation of CAES facilities.

As used in this report, "stability" of a storage cavern implies the extent to which an acceptable amount of cavern storage volume can be utilized with routine maintenance for a specified time interval, e.g., 35 years. In this context, cavern stability is relative to both planned utilization and time interval of operation.

Studies of long-term stability of various CAES concepts in different geologic media currently are underway (76). The study of this report is directed specifically to stability of caverns constructed in salt domes or salt anticlines. The first operational CAES facility at Neuenhuntorf, West Germany, also utilizes caverns in a salt dome for the air reservoir (78). 
Although the storage of liquid hydrocarbons has been practiced in United States (U.S.) Gulf Coast salt domes for around twenty-seven years, (41), the cyclic pressure and temperature variations which are an integral part of CAES operations introduce new considerations relative to the long-term stability of the associated storage caverns. Many hydrocarbon storage caverns now in operation are a secondary benefit of an original brine solution-mining operation and were not designed with stability as a primary concern. More recently however, energy utilization concerns have gained such prominence that optimizing cavern designs in salt domes for storage purposes has become a primary, rather than a secondary, consideration. Thus a great deal of interest now exists in further developing the technology currently associated with design of salt dome storage caverns, and extending this technology to implement relatively new storage concepts, such as compressed air energy storage.

\subsection{Objective}

The objective of this study was to review the existing literature and consult knowledgeable workers in the storage industry, and then report state-of-the-art findings relative to long-term stability of compressed air energy storage caverns in salt domes. Further, preliminary cavern stability criteria were to be presented in a form consistent with the amount of information available on cavern performance in salt domes. Another objective of this study was to outline a methodology for determining the long-term stability of site-specific CAES cavern systems in salt domes. 


\subsection{Significance}

The air reservoir obviously is a principal component of any CAES facility. Stability of storage caverns which comprise the air reservoir over the planned lifetime of a facility is essential for its continued utilization.

The development of a complete set of long-term stability criteria, including field verification, will make possible the application of rational engineering design principles to CAES caverns. The resulting benefits will include both increased efficiency and subsequent economy for facilities employing the CAES concept. An efficient CAES facility will make possible cost effective energy-peaking storage in the salt domes of the U.S. Gulf Coast region, and also in salt dome-like or anticlinal structures in other parts of the U.S.A.

\subsection{Scope of Study}

The scope of this study is limited to stability considerations for CAES caverns in salt domes and salt anticlines. Thus, the effects of surface facilities associated with CAES caverns are considered as they relate to cavern stability. However, details of surface facility machinery and systems, e.g., types of compressors or turbines, are beyond the scope of this study.

Most examples presented in this study deal with stability of salt dome caverns in the U.S. Gulf Coast region $(28,36,41)$. Since this is the only confirmed salt dome region in the U.S.A., the selection of local examples appeared appropriate. However, the same criteria discussed would apply equaliy to other areas of salt structures in other 
parts of the U.S.A. such as, for example, the Paradox Basin anticlines of Colorado and Utah. The U.S. Gulf coast salt dome region and the Paradox Basin of Colorado and Utah are depicted in Fig. 1.3-1., along with other salt deposits in the U.S.

At the present time, adequate field data do not exist to establish specific long-term stability criteria for CAES caverns in salt domes or salt anticlines. Thus preliminary generic stability criteria, bounded where possible, with associated methodology for site-specific development and implementation, are presented herein. The material presented in this report deals mainly with stability of non-compensated CAES caverns. However, a review of concepts relative to utilization of compensated caverns in salt structures is also outlined in order to compare stability effects for these two "competing" CAES concepts. 


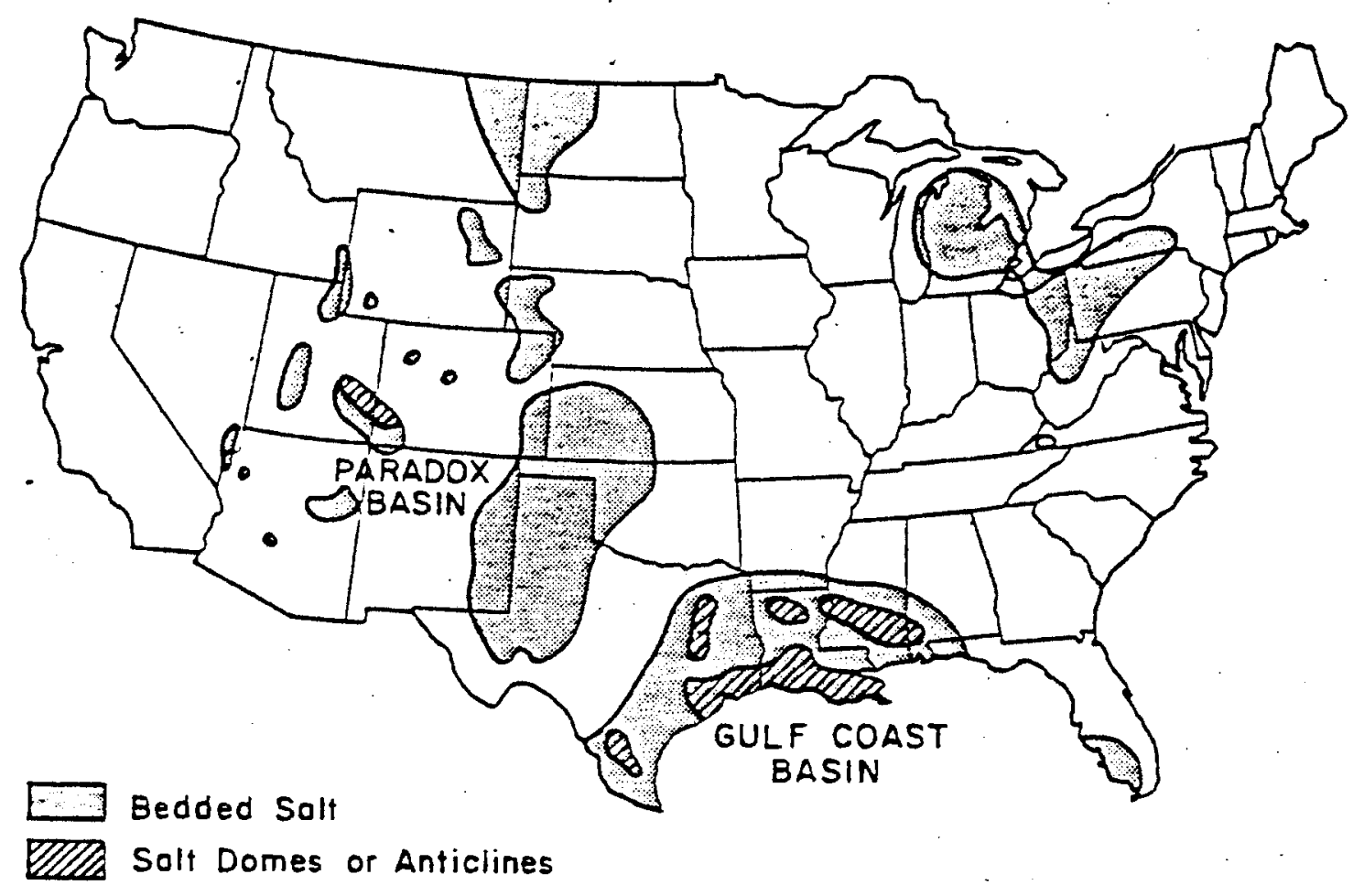

Modified from Johnson ond Gonzoles, $197 \mathrm{~B}$

FIG. 1.3-1. SALT DEPOSITS IN THE UNITED STATES 


\section{GENERAL STABILITY CRITERIA}

General stability criteria for long-term stability of CAES caverns in salt structures are summarized in this section. Detailed discussions and back-up reference materials are presented in the subsequent sections of this report.

\subsection{Summary of Factors Affecting Cavern Stability}

Table 2.1-1 lists general factors affecting long-term stability of CAES caverns in salt domes. General stability criteria related to these factors follow thereafter in a summary format.

- Site-Specific Utilization History of Domes.

- Geology of Salt Domes Including Caprock and Neighboring Formations.

- Material Properties of Salt and Adjoining Materials.

- Configurations of Dome and CAES Caverns.

- Loading Cycles for CAES Operations.

Table 2.1-1. General Factors Affecting Long-Term Stability of CAES Caverns In Salt Domes

\subsection{Principal General Stability Criteria}

- The site-specific utilization history of potential air storage salt structures should be researched to insure man-made effects will not threaten the integrity of the containing salt. For example, there must be an absence of man-made hydro fracturing connections or solution channels through the salt, possibly due to early brine production, that 
could open under CAES operations; and a good record of ability to maintain well casings through caprock (if any) into the salt. Any previous brine and/or sulphur mining operations in the caprock should be checked to insure that associated effects such as surface subsidence have essentially ceased, e.g., with levelling surveys, and will not otherwise significantiy affect a CAES facility (17).

- The geology of potential air-reservoir salt domes, including the caprock and neighboring formations, should be studied and reported in the early stages of planning for CAES facilities. For example, the presence of liquids or gases in the salt stock itself may not disqualify a potential storage dome. However, the presence of a highly permeable anhydrite sand at the caprock-salt contact could permit circulation of brines with $\mathrm{H}_{2} \mathrm{~S}$ gas that would cause rapid corrosion of well casings unless appropriate precautions are taken to obtain a continuous protective seal with a sulfate resistant cement. Leaks in casings could lead to an abrupt depressurization of CAES caverns with resulting damage to the surrounding salt ("wall slabbing" and "roof falls"). Furthermore, the geology of the salt, caprock, and adjoining formations is directiy related to the mechanical properties of the associated materials.

Salt domes display anomalous zones in which weaker salt, gas pockets, and hydrocarbons are present in the salt stock $(44,45,84)$. Megascopic features associated with these zones would directly affect CAES caverns. The geology of salt domes in the U.S. Gulf Coast generally varies in character, and should not be assumed to be the same even for domes separated only by a few miles $(7,45,84)$.

The state of tectonic stress within the salt stock of U.S. Gulf Coast domes is usually assumed to be hydrostatic in character. However, 
this assumption should be checked; and, it is suspect in the Paradox Basin salt anticlines. In both cases, the study of tectonic stresses within the salt stock deserves careful attention, because creep closure rates of caverns in evaporitic rock are strongly affected by the state of initial geostatic stress $(56,72)$.

An ideal CAES dome would include the following geological features: (1) massive anhydrite caprock (if any) free of vugs and lost circulation zones (where drilling "muds" are lost and cannot be recirculated), (2) solid caprock-salt contact, (3) relatively homogeneous salt of uniform character and free of liquid and/or gas.

- The material properties of the salt and adjoining geologic units, e.g., caprock, should be established so that stability analyses will have a basis for precluding cavern failure under environments associated with cyclic CAES operations. Currentiy there does not exist a material properties (mechanical, thermal, and chemical) data base for predicting the long-term response of rock salt subjected to cyclic loadings of pressure, temperature, and humidity typical of a CAES facility. Some creep data exists for laboratory specimens of rock salt subjected to elevated temperatures and varying load paths $(88,89)$. Also, a number of associated material "laws" have been proposed for numerical modelling applications $(11,12,16.23,52.80)$. However, for CAES operations, the important long-term effects of creep-rupture and low-frequency fatigue of rock salt in a cyclic environment are largely unexplored phenomena $(35,92)$.

Deterioration of salt around caverns also can be anticipated to depend upon site-specific material responses to a rapid drop of cavern pressure. For example, a pressure drop from 2,219 psi $(15,300 \mathrm{kPa})$ to $114 \mathrm{psi}(786 \mathrm{kPa})$ over 158 hours apparently caused a significant roof fall in an experimental gas storage cavern in a German salt dome (68). 
The topic of material properties of rock salt and the relationship to cavern stability is relatively complicated and somewhat lengthy. More detail on this topic is presented in Subsection 4.5. Included also is a brief review of methods for representing rock salt material response. Section 5. includes a program methodology for developing data specific to potential CAES operations.

- The configuration of a potential CAES dome must be capable of accommodating a system of caverns suitable for a compressed air reservoir. Depths of CAES caverns apparently can range from approximately 2000 to $5000 \mathrm{ft}(609.6-1524.0 \mathrm{~m})$. This assumes a maximum operating pressure of 100 bars $\left(10^{7} \mathrm{~Pa}\right)$. Minimum dimensions for salt "wall" thickness between caverns and "roof" thickness over caverns will require analyses utilizing site-specific material properties (response) associated with CAES loading environments. Examples of minimum wall thickness between storage caverns include $100 \mathrm{ft}(30.5 \mathrm{~m})$ for pseudo static hydrocarbon storage and $721.8 \mathrm{ft}(220 \mathrm{~m})$ for the two CAES caverns at Huntorf. Examples of cavern roof thickness include $200 \mathrm{ft}(61.0 \mathrm{~m})$ for hydrocarbon storage and approximately $328 \mathrm{ft}(100 \mathrm{~m})$ at Huntorf. These recommended and existing dimensions apparently are based mainiy on a great amount of first-hand experience in hydrocarbon storage and brining operations in the U.S. Gulf Coast and in West Germanv respectively $(75,21)$. In addition, the West Germany design reportedly incorporated data from model testing of rock salt along with a numerical analysis for a "check".

Cavern shape, size, spacing, and number obviously can all vary depending upon the requirements of any particular CAES facility operation. A systems optimization analysis should be used as a basis for establishing these parameters. Intercavern air flow effects, e.g., 
friction and thermal losses, along with total air volume flow requirements would necessarily be coupled with cavern system stability requirements in such an analysis.

The general CAES criteria for dome configuration requires that an adequate volume of salt must exist at a workable air reservoir depth so as to provide a surrounding envelope of salt sufficient to prevent the formation of connections from the reservoir to the dome surface. Such connections could be of a long-term progressive character, and would be due to a combination of creep-rupture, mechanical and thermal fatigue, air penetration, and hydro-fracturing effects.

- The loading cycles for CAES operations must range within bounds obtained from an engineering analysis and a verified data base. A verified data base necessarily will include field experiments within a potential CAES salt structure with observed test results correlating with predicted results from an appropriate analysis. The analysis should be based on a combination of laboratory and/or in-situ tests and numerical modelling. Since cavern pressure is the loading parameter most easily controlled under actual operating conditions, it should receive maximum attention in tests and numerical modelling simulating prototype CAES loading environments. However, at the same time, the dependent and coupled loading parameters of temperature and humidity also must be properly represented. It should be noted that most of the factors affecting long-term cavern stability under CAES operations could be strongly coupled.

The planned cavern pressure cycle at the Huntorf CAES facility includes charging for eight hours to $70 \mathrm{~atm}$, then discharging for two hours to $50 \mathrm{~atm}$. Another CAES study includes an example cycle with 
$24 \mathrm{hr}$. pressure variations of approximately $13 \mathrm{~atm}$. The daily cycle is embedded in a weekly cycle with approximate maximum and minimum values of 78 and $46 \mathrm{~atm}$ respectively $(86)$.

Based on physical model studies of rock salt behavior at elevated temperatures (48), a maximum allowable salt temperature of $80^{\circ} \mathrm{C}$ is postulated for CAES cavern walls. This does not imply that the maximum temperature of the air injected into the cavern is limited to $80^{\circ} \mathrm{C}$, as explained in more detail in Subsection 4.6 .

In addition to effects of CAES loading cycles on the rock salt around air-reservoir caverns, effects on well casings and "casing seats" into the salt also must be considered. Such effects are probably better understood (than effects on salt) by the storage industry operating in Gulf Coast salt domes. However, the progressive deterioration of casing-seat grouts should be explored under cyclic pressure and thermal loadings. The Huntorf CAES plant utilized an inner "free" tube to transmit air, thus uncoupling the outer well casing from thermal or pressure "shock" loading effects.

In summary of this section, general criteria for long-term stability of CAES caverns in salt domes have been reported; however, a data base specific to the cyclic loading character of CAES operations must be developed prior to specifying quantitative criteria with any degree of confidence. As noted previously, a methodology is proposed later within this report for establishing site-specific and quantitative criteria. More detail supplementing the general criteria presented in this section also is presented in the subsequent sections of this report. 
3. STATE OF THE ART SURVEY; PRINCIPAL FINDINGS AND RECOMMENDATIONS

A principal part of this report includes the findings from a stateof-the-art survey relative to long-term stability of caverns in salt domes. Attention was directed to information sources on aspects of stability which were particularly relevant to potential CAES operations in salt domes. Thus a literature survey was undertaken, and also discussions were held with persons experienced in the geostorage industry involving salt domes. The principal findings are reported in this section in summary format.

Some duplication of Section 2 on General Criteria etc. was inevitable, since the criteria for long-term stability were based in part on the Findings listed in this section. Also, additional details supplementing the summary statements of this section are presented in Section 4 .

A summary set of relatively brief and general Principal Recommendations also is included at the end of this section as a follow-through sequel to material presented in the Principal Findings.

\subsection{Principal Findings}

- Field data associated with storage of natural gas in salt dome caverns currently is most directly applicable to long-term stability studies of CAES caverns. Review of the geostorage related literature and discussions with operators of a variety of storage operations (hydrocarbons and/or brine) in salt domes have revealed significant amounts of data. However, the data typically is fragmented and not directly applicable to stability criteria for CAES operations. 
Field operations most similar to CAES currently exist in the natural gas storage industry. Experiences in storage of natural gas in salt dome caverns should be carefully evaluated in future planning of CAES operations. - CAES storage raises more concerns with stability problems than liquid hydrocarbon storage, solution mining, or natural gas storage currently operational in salt dome caverns. Long term cyclic loadings of pressure and temperature could have more deleterious effects on cavern stability than current psuedo steady-state storage operations in salt dome caverns. However, the extent of the possible increase in deleterious effects is currently unknown. Roof falls reportedly have occurred in conjunction with rapid pressure drops in salt dome natural gas storage caverns, which implies rates of pressure drops associated with daily CAES cycles could affect cavern stability. Surface contact by brine, as contrasted to gas, is believed by some investigators to increase the plasticity of rock salt (63). If this is true, spalling of the surfaces of "dry" CAES caverns might be more severe than for brine filled caverns under similar pressure and temperature loading cycles.

- A number of workers with field experience in the domal storage and mining industry are dubious about the significance of conventional rock mechanics laboratory testing programs relative to predictions of salt dome cavern behavior. They share a strong conviction that only field tests and related experiences under actual site-specific conditions can be relied upon at the present time to yield reliable results for predicting cavern behavior. Presumedly this conviction will change with evidence of benefits gained from successful cavern stability analyses which employ data obtained from relatively efficient laboratory and numerical studies. 
- Test caverns have been employed in West Germany to obtain field data for performance of natural gas storage caverns. Apparently no such scaled down caverns with tests have been utilized thus far in the United States (U.S.). "Pilot cavern" tests would be highly desirable for establishing cavern stability criteria, particularly for cyclic loading conditions. Some borehole test procedures have been proposed both in the U.S. and abroad as an intermediate method for obtaining data on in-situ rock salt performance that could be related to cavern stability.

- Laboratory testing programs for determining rock salt behavior have been conducted mainly with compression triaxial or uniaxial tests. However, more infrequently used triaxial extension tests were found to be of primary value in at least one major study of creep closure of salt dome caverns. Triaxial extension tests permit a more comprehensive evaluation of creep-rupture, which is a significant effect in long-term stability of openings in rock salt $(11,57,58)$.

- Crystal sizes (around $0.25 \mathrm{in} .(0.64 \mathrm{~mm})$ "diameter") in polycrystaline rock salt are relative large, thus scale effects are probable in laboratory tests with relatively small specimens. Some test data imply dependence on size of cylindrical rock salt specimens falls off sharply for 4 in. diameter (and above) cylinders with standard length to diameter ratios of 2 or slightly larger (24).

- Numerical modelling of rock salt behavior with the finite element method has been in use for some time. Numerical modelling can be employed as a powerful aid in developing and verifying stability criteria during the laboratory and in-situ testing phases as well as during the pilot cavern (if used) and field operational phases of prototype CAES air-reservoirs. 
- Empirical methods combined with field experience have been used successfully in cavern stability studies. The CAES caverns at Huntorf, West Germany, reportedly were designed primarily on this basis (Subsection 6.2.). - Stability criteria ul timately must be verified by field data from pilot and/or operational prototype CAES caverns. Relatively sophisticated monitoring equipment now exists for such purposes e.g., a laser ranging device that can monitor distances within a prototype gas-filled salt cavern under pressure with an independent sensitivity of $\pm 10 \mathrm{~cm}(59)$. Other sensitive monitoring equipment also may be useful for recording cavern performance, e.g., microseismic monitoring systems and tiltmeters.

- The study of fundamental rock salt mechanics for all kinds of storage in domes is still in a relatively early stage. The more complicated loading conditions associated with CAES caverns will entail a considerable amount of careful investigation before full confidence can be placed in associated specific and detailed quantitative long-term stability criteria.

- $\quad$ Concerns with compensated (constant pressure), as contrasted to noncompensated (constant volume), CAES caverns would include possible (1) erosion of salt in the air-reservoir "walls" and connecting openings due to liquid flow, and (2) abrupt loss of cavern pressure due to a champagneeffect blowout of the compensating saturated brine "leg" (10). However, compensated caverns would possess an apparent advantage of low amplitude cyclic pressure loading of surrounding rock salt.

\subsection{Principal Recommendations}

- Long-term stability criteria for CAES caverns should be concerned with effecting acceptable limits on time dependent creep closure, creep 
rupture (spalling or slabbing), and superimposed deleterious cyclic loading effect. However, short-term effects that could threaten the overall integrity of the air-reservoir also must be limited, e.g., hydrofracturing, well casing failure, and cavern roof and wall "falls" due to abrupt depressurization.

- Specific long-term stability criteria for CAES caverns should be developed in a closely coordinated and balanced program utilizing complementary: (1) laboratory and/or bench-scale testing of site-specific salt, (2) numerical modelling, and (3) field testing. The CAES study outlined by Battelle, P.N.L., incorporates the necessary features for such a program.

- Correlation studies should be performed on results from laboratory and/or bench-scale tests, borehole and/or model cavern tests, and prototype cavern tests. Consistent findings relative to long-term cavern stability then could be used to develop an optimum testing program for determining necessary site-specific input parameters for stability criteria. Such a program would be extremely valuable in planning additional CAES cavern systems and operations in salt domes. - Table 3.2-1. is a summary list of topics which should be studied to obtain additional information relative to long-term stability of CAES caverns in salt domes. Reasons for studying these topics are discussed in more detail in the subsequent sections of this report. 
- Long-Term Creep, with Creep Rupture, of Rock Salt.

- Effects of Pressure and Temperature Loading Rates.

- Low Frequency Fatigue, with Coupled Cyclic Pressure, Temperature, and Wetting Conditions.

- Progressive Air Penetration of Salt Fabric.

- Cavern Monitoring Methods.

- Correlation of Laboratory, Analytical, and Field Results.

Table 3.2-1. Topics for Additional Study Relative to LongTerm Stability of CAES Caverns in Salt Domes. 


\section{FACTORS AFFECTING CAVERN STABILITY IN SALT DOMES}

\subsection{Genera1}

The diapiric salt stock, caprock (if present), and surrounding affected geologic units associated with a salt dome can be defined to comprise a geomechanical system $(82,83)$. (This definition is patterned after the generalized definition of a mechanical system as "anything composed of matter" (46). CAES caverns emplaced in this geomechanical system will be treated as a subset of the system in this report. This concept has been adopted with the objective of achieving a general view of long-term stability effects related to CAES caverns.

Before proposing stability criteria, the factors affecting stability of caverns in salt domes obviously must be considered. These factors have been identified in varying degrees by: (1) searching appropriate relevant technical literature; (2) interviewing personnel of companies with operating experience in cavern storage; and (3) discussing research findings and concerns with workers in rock salt mechanics.

Investigations carried out under the auspices of this and other studies have revealed that the field of rock salt mechanics currently is in an early stage of development. For example, with regard to the previously cited sources of information for identifying factors affecting cavern stability: (1) A relatively large amount of observational literature exists on the art of storage in salt domes, but little literature exists which relates engineering design concepts to subsequent field performance. (2) Relatively few companies possess operating experience in storage of gases in salt dome caverns; and these companies seldom 
publish technical data on field performance of operating caverns. Petroleum related industries traditionally are highly competitive enterprises, and specific technical practices and results are generally considered proprietary. (3) Furthermore, relatively few institutions, both public and private, are engaged in rock salt mechanics studies. Consequently, there is now only limited agreement among a relatively small number of researchers on consistent analytical descriptions and preferred experimental procedures for typifying rock salt behavior insitu.

The preceding comments are not intended to signify pessimism at the recognition of a complicated problem; but rather to emphasize the authors' attitude that the long-term stability of CAES caverns justifies a corresponding and ongoing long-term careful study.

The factors potentially affecting stability of CAES caverns are presented in the following subsections. The subsections are ordered generally from those factors over which there is little control (except to avoid certain features where possible) to those factors which can be controlled by facility operators.

\subsection{Site-Specific Dome Utilization History}

A number of salt domes in the U.S. Gulf Coast have a history of sulphur mining, uncontrolled ("wild") brine operations, and other generālly poorly defined early utilization activities. Such activities potentially could affect a proposed CAES facility. Careful study of all historical records of dome utilization and discussions with local area residents should be carried out to determine the current status of any particular potential CAES dome. 
Some early brining operations have caused surface sinkholes to develop. Sinkholes apparently caused by early "wild brining" operations are associated with the following domes: (1) Blueridge near RichmondRosenberg in Texas (31 (1949)), (2) Grand Saline near Tyler, Texas (1976), (3) Bayou Choctaw west of Baton Rouge, Louisiana (49 (1954)), and (4) Spindletop (sulphur production) south of Beaumont, Texas (date unknown).

The Blue Ridge dome sinkhole development was well documented and displayed photographically by Hanna (31). Recently (circa 1977) an accident allegedly involving an explosive gas was reported over the Blue Ridge dome. Two LPG storage caverns were being operated in the same dome. Although not conclusive, this collection of available information suggests the integrity of the dome in the close vicinity of the previous sinkhole had been affected. It would reflect nonconservative engineering judgement to consider placing a CAES air-reservoir in an area obviously suspect of potential gas leakage.

Prior to the development and utilization of Sonar to determine cavern configuration, solution cavities caused by brining operations within domes were essentially unknown with respect to volumetric extent. Even today the existence of solution channels behind anhydrite stringers within caverns may be undetected by Sonar techniques. Thus it is particularly difficult to establish the full extent of openings in salt domes formed by early brining operations with "air lifts" and without protective oil "blankets" to limit cavern roof dissolution. "Air lifts" refer to injecting air at depth in a cavern, subsequently "lifting" the brine to the surface through well casings.

A history of subsidence due to sulphur mining also should be carefully reviewed (17). Man-made channels that enhance circulation of corrosive 
brines and gases at the dome-caprock interface can affect well casings and surface facilities associated with a CAES facility.

In general, domes with a history of extensive early brining and sulphur mining activities should be avoided if alternate domes without this history are available. In any event, the history of all existing caverns in a potential CAES dome should be reviewed with particular attention being paid to Sonar surveys delineating cavern configurations. Current solution mining methods can be employed to obtain a desired smooth cavern configuration without difficulty in a homogeneous salt stock. However, the presence of relatively insoluble anhydrite "stringers" or gas pockets in a salt stock will cause local irregularities in an overall cavern configuration.

The possibility of previous brine production between caverns or wells also should be explored. Hydrofractures in salt are reported to "heal" superficially, only to reopen when some limiting threshhold pressure is attained. Such phenomenon would be highly undesirable for CAES operations.

\subsection{Geologic Features of Salt Domes}

The geology of salt domes generally defines the megascopic features important to CAES operations in a particular dome. Such features, which are of concern for engineering design purposes, are so large that they cannot be readily analyzed on the basis of laboratory or even bench-scale tests (60). A number of megascopic features potentially affecting CAES caverns are disucssed in the following paragraphs.

In a number of domes that have been solution mined for brine there exists a preferred direction of dissolution. For example, a number of relatively shallow solution caverns in the Choctaw salt dome near Baton 
Rouge, Louisiana, display definite trends of northeasterly to southwesterly elongation in horizontal cross sections at shallow depths (77). Normally, solution mining results in caverns with approximately circular horizontal cross sections; thus the consistent elongations of cross sections probably result from preferred dissolution directions in the salt. This also would suggest preferred directions for principal material axes (anisotropy) in the salt dome on a megascopic scale. The main effects of material anisotropy on this scale would be to influence the shapes of CAES caverns formed by solution mining, and possibly also to imply a preferred direction for potential "hydro-fracturing" should pressures become excessive. Weak salt, gas, brine, inclusions and gas outbursts are known to occur in spatial trends or "zones" over some Louisiana salt domes mined by the room and pillar method $(44,45,84)$. Such trends are possibly the chief concern with the integrity of salt domes for all kinds of storage. In the generally homogeneous and relatively light salt of these mines, few problems exist relative to brine, gas and wall spalling or roof falls. Furthermore, the salt in such areas is relatively impermeable. However, in the trend zones the salt is darker (because of impurities and higher anhydrite content), and exhibits generally undesirable features of inhomogeneity, structura 1 weakness, and relative permeability. Whether these features "die out" with greater depth remains to be investigated. In any case, the intersection of such zones with CAES caverns must be avoided; otherwise the integrity of the air reservoir could be jeopardized. Establishing the locations of these trends or "zones" apparently can be accomplished only by thorough geological investigations, including coreholes. It has been suggested that some indications of such "zones" may be obtained by mapping the dome surface with 
complementary shallow seismic methods. Other potential indirect methods include gravimetry, magnetometry and acoustic holography.

Certain domes are active "solution" domes, that is, a highly permeable zone exists between the salt surface and caprock $(9,39)$. Such zones are so extensive as to accommodate large amounts of drilling mud by direct loss during drilling operations. The Winnfield Dome, for example, has a layer or seam of highly permeable anhydrite sand varying from six inches to several feet thick between the salt and caprock (W.H. Cameron, former mine manager, personal communication, 1977). If a high rate of circulation exists in this sand, it will tend to corrode any unprotected well casings and other pipe connecting the CAES caverns to surface facilities. Construction problems also could be incurred because of this porous zone.

The caprock also can be cavernous and vuggy. If lost circulation occurs during drilling the hole can collapse; but, specifically from the long-term stability viewpoint, a cavernous caprock will tend to increase well casing corrosion problems. Unprotected well casings can corrode and leak within a decade under such conditions. A leak in the casing can directly affect stability by permitting a rapid pressure drop within a cavern. Rapid pressure drops in rock salt storage caverns, as noted previously, have apparently precipitated roof falls, and thus are highly undesirable from stability considerations.

\subsection{Geometrical Configuration}

The geometrical configuration of the geomechanical system comprised of the salt stock, caprock, and adjoining units (as defined in Section 4.1.) will affect both short-term and long-term cavern stability. That 
is, the behavior of mined openings in salt domes, both during construction and thereafter, will be directly affected by configuration of the geomechanical system. It follows that any analys is of long-term cavern behavior will generally require a relatively complete knowledge of the geomechanical system configuration.

As used herein, the system configuration includes the relative positions of all geological units comprising the salt dome system. Typically the system configuration is specified by horizontal and vertical (depth) dimensions for: (1) major geologic units in the overburden (above any existing caprock) and surrounding materials; (2) caprock; and (3) salt. The depths at different locations are referenced to mean sea (or Gulf) level and horizontal distances to conventional surveying monuments at the ground surface.

The configuration of the system can be determined to varying degrees of detail by a combination of geophysical methods, e.g., seismic and gravity techniques, and by reference to drilling data $(50,87)$. Drilling data are usually considered as control points for the seismic data; however, the sources of such logs should be carefully reviewed prior to weighing then with a high level of confidence.

The typical sedimentary sequence intruded by a salt dome is highly variable vertically in lithology; and with facies changes, can also vary horizontally. This variability is enhanced by such structural changes as faulting due to the upward diapiric movement of the salt stock $(7,55)$. In some instances the salt stock has an "overhang" on the periphery. Locating the dome flanks under such overhangs is a more difficult problem than mapping the upper surfaces of the system. Slant drilling and more 
sophisticated (and expensive) geophysical methods can be employed if such data is required in detail.

The configuration of the CAES caverns relative to that of the dome system is controlled by design and solution mining techniques. With reference to Fig. 4.4-1., primary dimensions include depth to cavern roof, floor, and associated horizontal dimensions. The initial borehole location is used as a reference for locating horizontal cavern dimensions.

Significant configuration parameters directly affecting cavern stability include cavern depth, size and shape. Depth can be specified by cavern floor (or roof) elevation $\left(h_{f}, h_{r}\right)$, size by typical dimensions such as cavern height $(H)$ and diameter (D), and shape by a factor such as average diameter/height ratio $(D / H)$. "Bounds" on the shape factor include an infinite vertical cylinder $(D / H \rightarrow 0)$, and a sphere $(D / H=1)$.

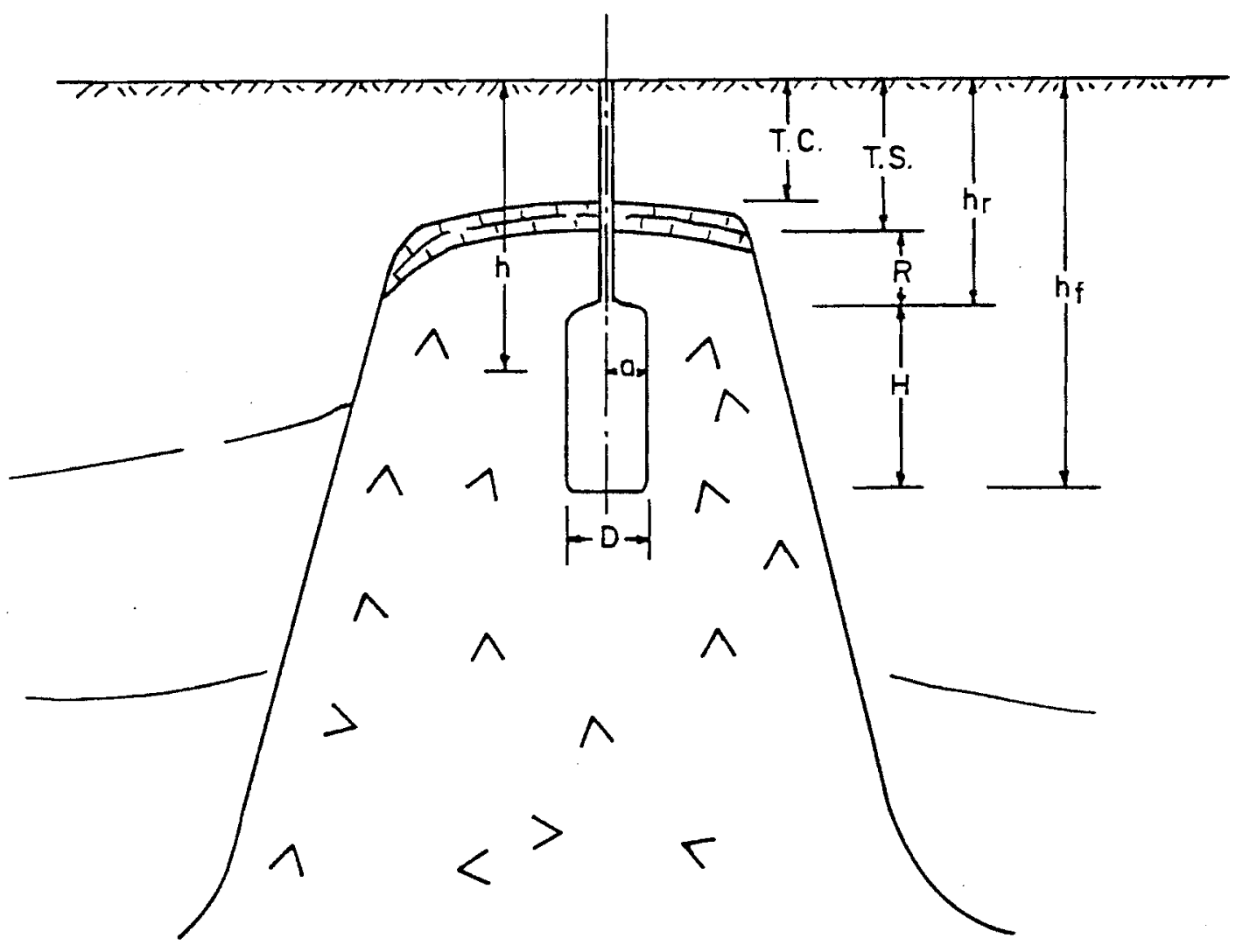

Fig. 4.4-1. Typical Dimensions Specifying Configuration. 
The first case obviously is not attained in practice, but can be employed as a conservative design check in cavern stability analysis. Driller's logs typically include elevation of "Top of Caprock" (T.C.) and "Top of Salt" (T.S.), as depicted in Fig. 4.4-1., and also "Total Depth" (T.D.) of the exploratory borehole (71). Cavern salt "roof" Thickness can be specified by $R$, and depth to an arbitrary point by $h$.

Feasible depths for CAES caverns in salt domes necessarily will be influenced by site-specific material properties of the salt and also by the operating cycle of the surface plant. However, a general range of feasible depths can be estimated, with more confidence in limits on minimum depth than on maximum depth.

A minimum depth to cavern roof (and well casing "seat" into the salt) of $2000 \mathrm{ft}(609.6 \mathrm{~m})$ would be consistent with an allowable maximum operating pressure of approximately 124 bars (12.4 MPa) for static storage of hydrocarbons in Louisiana salt dome caverns (75). That is, allowable cavern pressure at the casing seat $=0.9(2000)=1800 \mathrm{ps} i=$ 124 bars. Since cyclic loading effects probably will be more severe, CAES caverns at a given depth should have a maximum operating pressure which is less than the allowable for the static case. Thus a maximum operating peak pressure of approximately 100 bars (10 MPa) appears reasonable for a CAES cavern with roof and well casing seat at $2000 \mathrm{ft}$ depth. Alternately, for CAES pressure cycles with maximum pressure of 100 bars (10 MPa), cavern roof depth should not be less than approximately $2000 \mathrm{ft}(609.6 \mathrm{~m})$.

Allowable maximum depths for CAES caverns are more difficult to estimate. The pressure difference, $(g-p)$, tends to drive surrounding rock salt into caverns resulting in progressive creep closure. The rate of closure will be strongly affected by site specific mechanical properties 
of the salt. Furthermore at greater depths, the stress in the salt stock, $g$, associated with overburden pressure obviously is larger; and thus a rapid pressure drop in a deeper cavern will cause a corresponding rapid increase of $(g-p)$ to relatively large magnitudes. This will increase the probability of roof falls or other undesirable brittle material behavior in the rock salt surrounding the cavern.

The natural gas storage caverns in the Eminence dome in Mississippi reportedly underwent a $40 \%$ volume reduction within a few months after completion (21). Roofs and floors of the two caverns were at approximate depths of 5700 and $6700 \mathrm{ft}$ respectively $(1737.4-2042.2 \mathrm{~m})$.

Although the rock salt behavior around the Eminence caverns may have been anomalous for U.S. Gulf Coast Domes, it would be nonconservative to propose preliminary long-term cavern stability criteria that do not take into account this field example of undesirable behavior of a gas storage cavern. Thus, maximum depths of CAES caverns tentatively should be limited to less than approximately $5000 \mathrm{ft}(1524.0 \mathrm{~m})$, unless additional studies can be carried out that indicate greater depths are feasible.

In all cases, conventional well caliper surveys should be run to total depth of any exploratory borehole at a potential CAES cavern site. By running the survey twice, once immediately after drilling and then a few weeks later, e.g., four,; a site specific measure of the stability of the rock salt can be obtained based on the amount of borehole closure. Another configuration consideration potentially affecting cavern stability includes proximity of CAES caverns to other caverns (if any) in the salt dome. This consideration entails analysis of potential hydrofracturing (and pneumatic fraturing) between caverns, and other possible coupling effects. "Wall" thickness (minimum horizontal dimension 
between neighboring cavern surfaces) usually is specified as a characteristic spatial dimension for purposes of analysis provided the caverns are at the same elevation. More general 3-D configurations of neighboring caverns are usually described with detailed drawings or models.

With reference to Fig. 4.4-2, wall thickness $W$ between caverns has been specified to be a minimum of $100 \mathrm{ft}(30.5 \mathrm{~m})$ for storage of hydrocarbons (either gaseous or fluid) in salt domes in Louisiana (75). The two CAES caverns at Neuenhuntorf are separated by approximately $220 \mathrm{~m}$, with cavern diameters $D$ of $40-45 \mathrm{~m}$, and heights of approximately $150 \mathrm{~m}$. The minimum distance, $\mathrm{B}$, between hydrocarbon storage caverns and dome surface has been set at $200 \mathrm{ft}(61 \mathrm{~m})$ in Louisiana. This figure can be used for guidance in preliminary estimates of a "safe" salt thickness around CAES caverns.

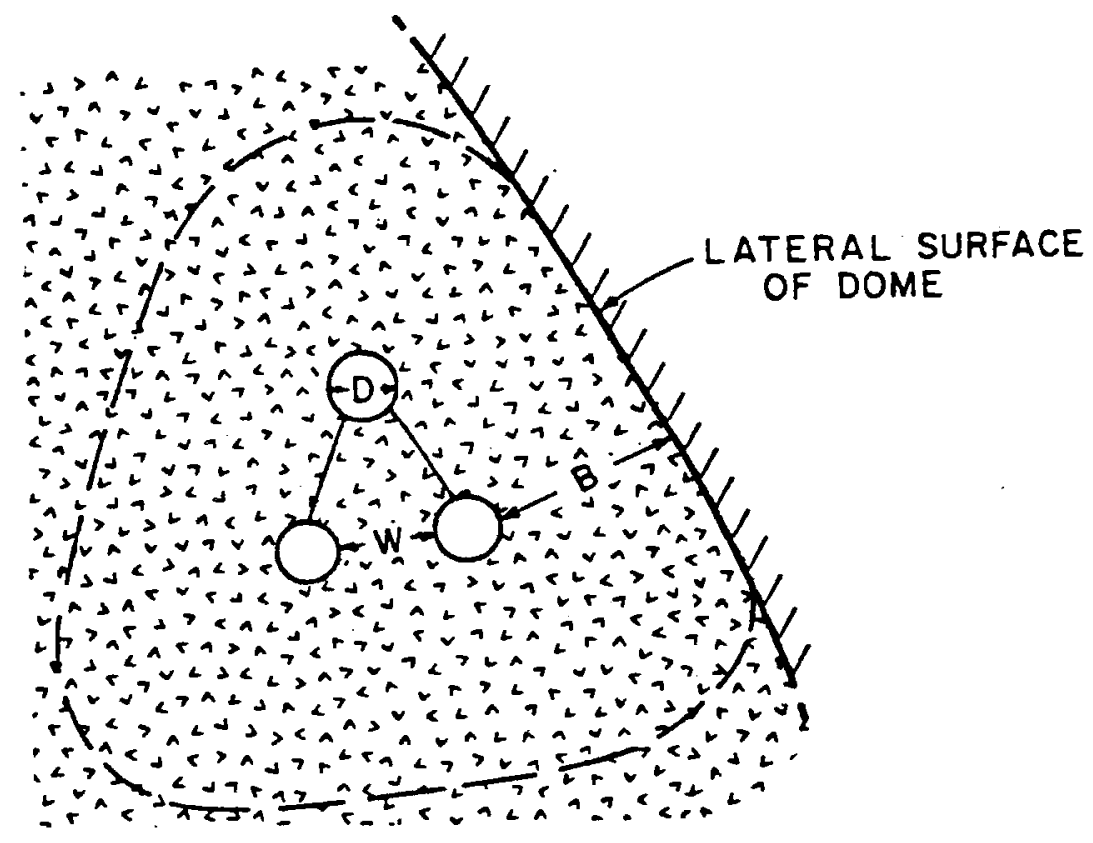

Fig. 4.4-2. Horizontal Dimensions of CAES Cavern System 
In conclusion of this subsection, serious problems have occurred in the domal storage industry in the U.S. Gulf Coast because caverns were constructed too close to the dome boundaries. In these cases, the boundaries of the dome were not well located. Obviously it is essential to obtain an adequate knowledge of the configuration of any geomechanical system considered for CAES caverns prior to the initiation of site specific designs. The boundaries of salt domes must be regarded as zones, particularly if they are not well located surfaces, for practice of conservative design principles.

\subsection{Material Properties}

Principal material properties and associated test methods are reviewed in qualitative terms in this subsection. Material properties of all components of a salt dome geomechanical system have potential influence on long-term cavern stability. The properties of the rock salt surrounding a cavern have dominating influence, with those of the caprock and intruded and adjoining sediments having respectively decreasing influence. U.S. Gulf Coast salt dome stocks usually are considered to be typified by relatively pure, homogeneous rock salt. However, generalizations about the similarity in material behavior of Gulf coast rock salt are currently in a state of review. That is, more study is required to develop a broader basis before characterizing the behavior of Gulf coast rock salt. Properties of Gulf Coast rock salt are not "all alike" from dome to dome, and usually vary within any one dome. Megascopic features of a particular dome will greatly influence the material properties of the salt stock on a global scale, as noted previously in Section 4.2.

For a complete analys is of cavern stability, both the salt stock and adjoining geologic materials should be characterized by numerical 
parameters in association with appropriate analytical material models. At the present time there is not general agreement among researchers as to the best method of characterizing long-term behavior of rock salt. This is apparent from recent technical reports of a variety of testing methods, means of interpreting data, and analytical material models, e.g., creep "laws". Some recent reports will be noted here for illustrative purposes.

Relatively sophisticated laboratory testing of rock salt has been reported recently by Wawersik, who also indicates that material state variables apparently are coupled in rock salt response (88). Hansen also has reported test results for rock salt, using testing machines based on designs by Wawersik (32). Some test data imply that results are influenced by specimen size for Jefferson Island rock salt (domal) cylinders of less than 4 in. diameter (24).

Testing machines capable of applying 3-D stress environments have been reported by Albrecht and Langer (2), Serata (74), and Winkel, et al., (91). A relatively simple and more conventional triaxial machine has been described by obert for testing rock specimens under stress environments typical of shallow depths of $5000 \mathrm{ft}(1525 \mathrm{~m})$ or less $(60)$. King and Acar employed somewhat similar machines to obtain creep data for potash over time periods up to $1000 \mathrm{hr}$ (43).

Analytical material models for rock salt have been proposed recently by Fossum and Russell $(23,70)$. Hansen evaluated Fossum's creep "law" relative to test data (32). Heard and Russell suggested the use of constant strain-rate tests as significant testing methods for obtaining data on long-term behavior of rock salt $(37,70)$. Rokahr, et al., have employed more traditional plasticity concepts and a power "law" creep 
formulation in an analytical description of time dependent rock salt response (69). Pariseau also has employed classic plasticity formulations to represent material behavior of rock salt mine pillars (64).

Fairly extensive materials properties data exists for the Tatum Dome salt in Mississippi as a result of the "Project Dribble" study performed in the early 60's $(11,66,85)$ by the Atomic Energy Commission $(A E C)$. In this study an atomic device was detonated within the Tatum Dome. Geophysical exploration, coring of salt and caprock, and associated testing were performed during the study. Some typical results from Project Dribble are presented in this section to exemplify data obtained by more traditional geotechnical testing methods.

Some test data also exists for the Winnfield Dome in north Louisiana (27). "Project Cowboy" was carried out in the Winnfield Dome by the AEC, also in the early $60^{\prime} \mathrm{s}$. In this study a conventional explosive device was detonated in a mined spherical opening in the dome.

Relatively little data exists on the material properties of caprock or country rock (typically sandstones and shales) surrounding salt domes at shallow depths $(1000-5000 \mathrm{ft}(30.5-1525.0 \mathrm{~m}))$. Some data exists for such rocks at depths of interest in $0 i 1$ production (29); however an "information gap" apparently occurs at the depths of interest for CAES air-reservoirs.

In-situ testing methods have received increasing attention recently in geotechnical engineering (3). For rock salt mechanics in particular, where large crystal sizes are frequently encountered, in-situ tests appear particularly appropriate. Furthermore, because of the relatively extreme friability of rock salt, as compared to other rocks, stress relief and coring methods can cause damage to the fabric of potential 
test specimens. The effect of such damage remains to be determined; however its extent should be noted by laboratory workers.

Borehole loading and monitoring techniques have been proposed for in-situ tests of rock salt $(13,83)$. Borehole testing instruments also have been developed $(26,30,54,73)$. Such tests could yield new information because the greater portion of the "specimen" (walls of the borehole) was relatively undisturbed. Such data should fill an important gap between laboratory tests and "pilot" size test caverns.

A particularly interesting pilot cavern study was reported recently (65). The study involved natural gas storage in bedded salt, and included the construction of a $4 \mathrm{ft}(1.22 \mathrm{~m})$ diameter by $24 \mathrm{ft}(7.32 \mathrm{~m})$ long cylindrical cavern in a bedded salt mine. The pilot cavern was heavily instrumented and then loaded by internal pressure to simulate operating conditions. Among other interesting results, the cavern apparently exhibited a time dependent "healing" capability, to near original response characteristics, following a loading-to-"failure" pressurization.

In considering laboratory versus in-situ tests, the fundamental "trade-off" occurs between degree of specimen disturbance and degree of information on boundary conditions, respectively. Both types of tests appear appropriate to rock salt mechanics, with correlation of data ultimately required.

Rock salt behavior may be typified using time as a general reference parameter. Fig. 4.5-1., schematically illustrates the general features of rock salt response during a typical laboratory "creep" test. For a creep test, a constant state of stress (load) is applied at time $t_{0}$ and maintained constant for the duration of the test. Strain is monitored 
and plotted as a function of time. A family of such curves can be ob= tained for a set of loadings which are selected so as to span the stress state anticipated around a cavern.

With reference to Fig. 4.5-1., rappiication of an "instantaneous". load to a salt specimen at time $t_{0}$ results in: (1) an "immediate" nonlinear displacement (or strain) response $\varepsilon_{0}$, (2) a time dependent creep response $\varepsilon_{c}$ which accumulates with time $t$, and (3) a possible rupture at time $t_{f}$, provided the salt is in a loading mode permitting rupture. The time interval, $t_{0} \leq t \leq t_{f}$, of the test is traditionally divided into three idealized subintervals or phases of material creep response, i.e., transient, steady-state, and tertiary. Rock salt typically exhibits a prolonged steady-state creep phase (which is not obvious in Fig. 4.5-1.), provided the applied loading state is not so severe as to cause transient and tertiary phases to completely dominate specimen behavior. The steady-state phase of rock salt response is of particular interest to long-term stability concerns of storage caverns; provided of course, an acceptable phase of transient response can be accommodated.

The significance of data from laboratory creep tests must be carefuliy analyzed prior to interpreting associated rock salt behavior in-situ. For example, the "immediate" application of loading in the Taboratory test, which directly affects the "immediate" strain so and the transient phase of materiat response, does not occur during the "construction" of a solution mined cavern in rock salt. Furthermore, the tertiary phase of rock salt response may not appear in a triaxial compression creep test due to extreme plastic flow. The plastic flow 


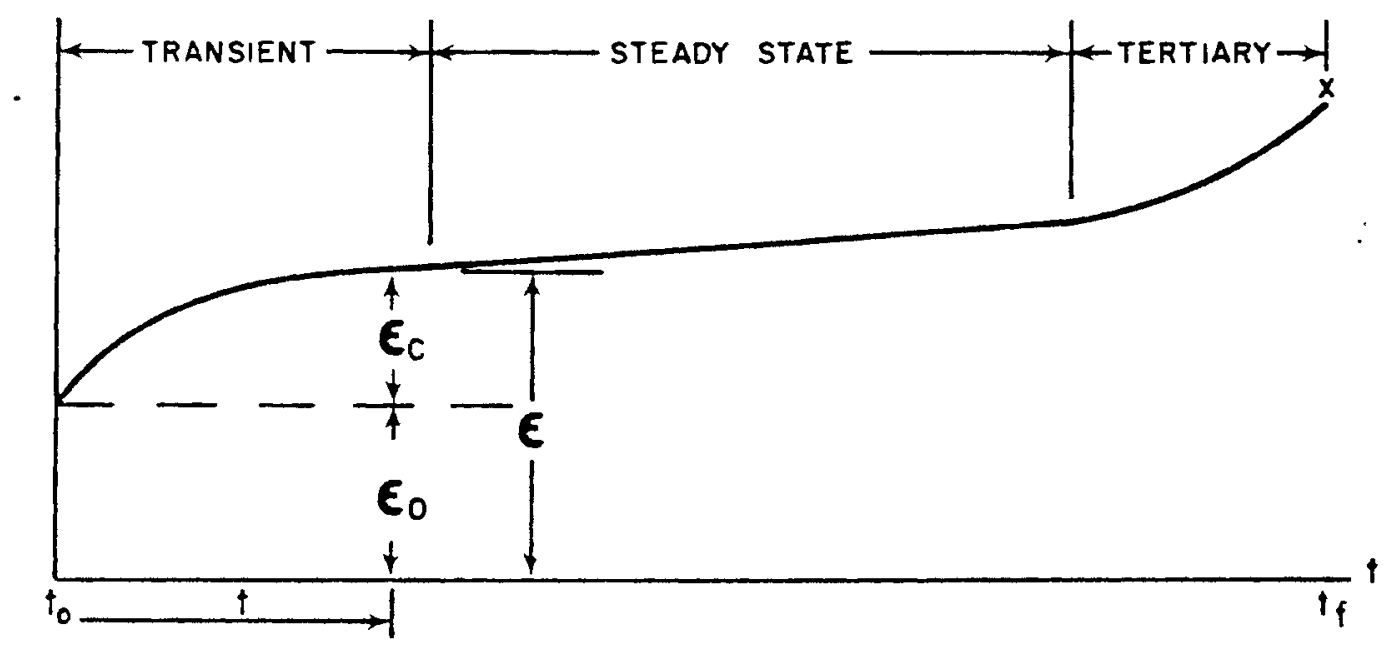

Fig. 4.5-1. General Response of Rock Salt to Load Applied at $t_{0}$ characteristics of rock salt become obvious if a relatively smali (500 psi $(3,447 \mathrm{kPa})$ or larger) confining lateral pressure is applied in a triaxial creep test (11).

An analytical description of rock salt response, with reference to Fig. 4.5-1., is,

$$
\epsilon=\varepsilon_{0}+\varepsilon_{c} \quad 4: 5-1 \text {. }
$$

where $\varepsilon$ and $\varepsilon_{c}$ are obviously time dependent. Aiso,

$$
\varepsilon_{c}=f(\sigma, \varepsilon, T)
$$

where $\sigma ; \varepsilon$, and $T$ denote stress, strain, and temperature respectively.

Generalized versions of equations (4.5-1) and (4.5-2) involve second-order tensor descriptions for material response. However, for most geotechnical applications, assumptions of material symmetry permit 
adequate descriptions with matrix notation and "reduced" vectors for both 3-D and 2-D states of stress and strain.

The determination of so usually proceeds by assuming the salt to be an "elasto-plastic" or nonlinear nonconservative material. Computer programs utilizing the finite element method have been developed to numerically model nonlinear geotechnical engineering problems. The origins of such programs, for the most part, can be related directly to programs developed originally for structural mechanics applications to nonlinear problems in the aerospace industry in the early and mid 60's (93). Applications to geotechnical problems quickly followed, along with early recognition of difficulties inherent in representing the nonlinear behavior of rocks and soils (67). Thus, although the concept of a temperature dependent "yield surface" for salt, along with other concepts bascially inherited from the study of structural metals may be questioned, the associated numerical and experimental techniques and machinery already in existence frequently makes the utilization of such concepts expedient. See, for example, the text by Zienkicwicz, 1977, (page 467). Furthermore, much of the numerical "machinery" necessary in a program to represent nonlinear time independent behavior also can be used to handle creep representations (93, page 476).

A general discussion of methods for the determination and/or description of so for a 2-D or 3-D loading state is beyond the scope of this report. Texts by Desai and Abel (19), Zienkicwicz (93), and the geotechnical literature $(64,67)$ may be surveyed for this purpose.

Test data to indicate "time independent" behavior of rock salt is usually obtained by "quick" triaxial tests (e.g. stress rates on the order of $20 \mathrm{psi}(137.90 \mathrm{kPa})$ per second $(66,85)$ resulting in plots of some 
stress measure versus a corresponding strain measure. The measures plotted usually are preselected to be consistent with the adoption of some material model. The behavior of the salt is influenced by the loading history and environment, including stress state, crystal grain boundary state (e.g. wetness), temperature, and loading rate $(1,48,53$, $63,68)$. Figure 4.5-2. depicts typical stress-strain curves from triaxial tests on Tatum dome salt (11). The ordinate of these curves is the difference in the principal axially and laterally applied stresses $\left(\sigma_{1}-\sigma_{3}\right)$, ( also called effective stress). This stress measure is conventional in geotechnical engineering. See, for example, the test by Desai and Abe1, page 93. In general, both temperature and loading rates should be included in data from rock salt testing.

If rock salt is unloaded and reloaded in a "quick" test, it exhibits strain hardening characteristics $(20,89)$. That is, it will unload along an approximately straight line and then reload along essentially the same straight line until the nonlinear "original" load-displacement curve, similar to those depicted in Fig. 4. 5-2., is intersected. Thereafter the nonlinear load-displacement curve is followed unless unloading again occurs. This material behavior implies that short-term cyclic pressure loading effects in rock salt associated with CAES cavern operations may be analyzed in part with effective linear reaction moduli.

Other data that can be obtained from "quick" triaxial tests include Mohr-Coulomb envelopes. The Mohr-Coulomb failure criterion also is widely used in geotechnical engineering $(19,92)$. As depicted in Figs. 4.5-3. through 5., the format used for plotting test data frequently implies the adoption of certain material models, as noted previously, to describe "yield" or "strength" behavior of salt. 


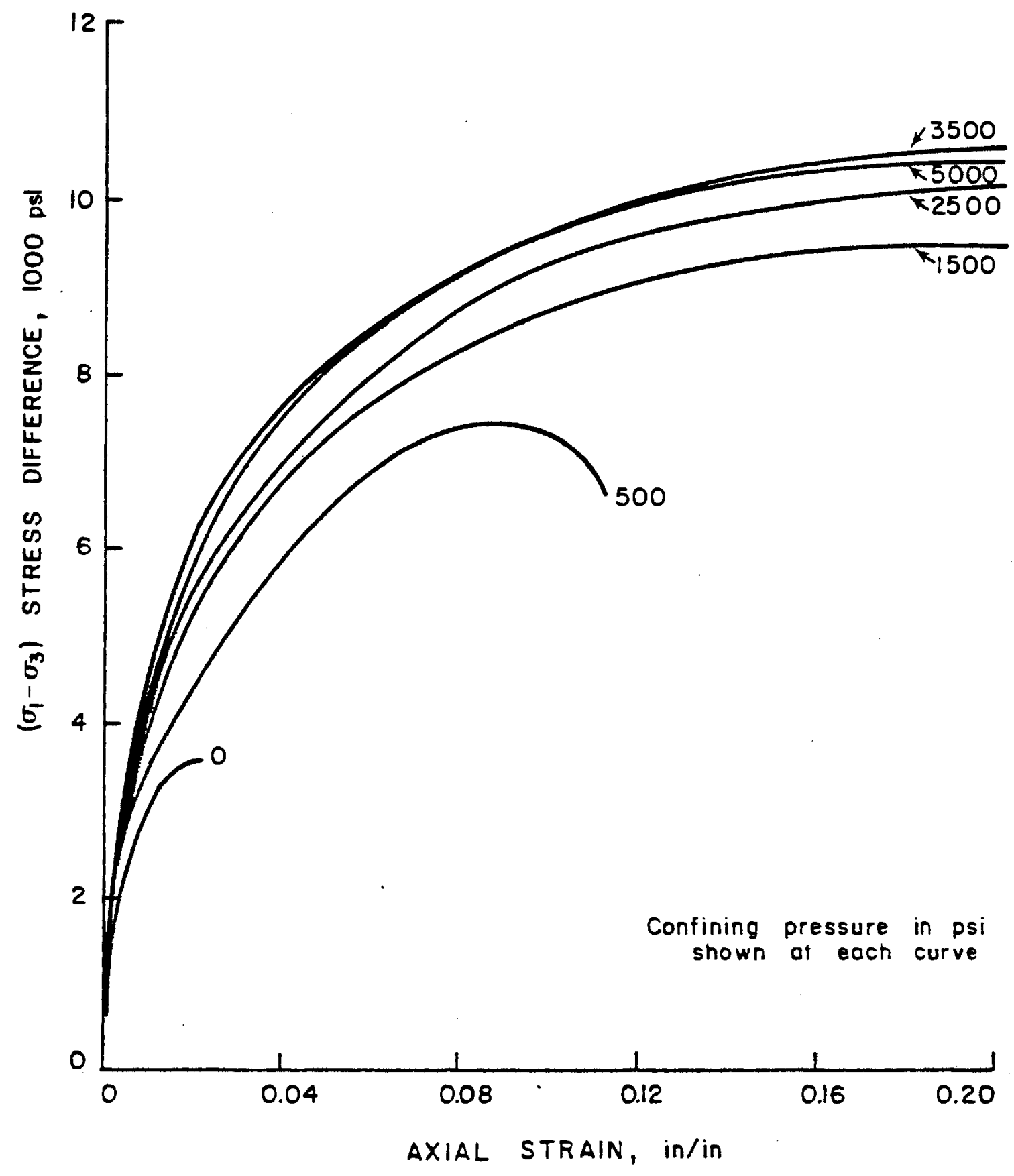

Fig. 4.5-2. Typical Stress Strain Curves For Rock Salt. (After Reference 11). 
One typical feature of such material models may include a failure or yield criterion of the form,

$$
f(\sigma, \varepsilon, T)=0
$$

This relationship implies, in general, that the material will fail, or undergo an increment of plastic strain according to some flow rule, when the state of stress (or/and strain and temperature) exceeds a "surface" defined in stress (or/and strain and temperature) space (93). An associated testing program must yield data adequate to define the failure or yield surface for loadings of interest. An inadequate material model implies the postulated failure or yield surface will not work for extrapolation of laboratory test results to material response under more general loading environments of interest.

The conventional geotechnical concept of time independent "strength" is difficult to define for rock salt unless the loading rate is relatively high; and in fact, will not be a principal criterion for longterm stability of storage caverns within salt stock. For example, in Figures 4.5-3. through 5., "strength" had to be defined in terms of percentage deformation (strain) (85). The rock salt reportedly would not exhibit fracture or a rapid loss of load carrying ability under compressive traixial loading conditions of the confining stress exceeded around $1500 \mathrm{psi}(10,341 \mathrm{kPa})$. By contrast, long-term failure of rock salt, in a progressive spalling mode, can be associated with time dependent extensional creep and related creep rupture $(11,57,58)$.

As noted previously, the determination and/or description of time dependent creep of rock salt has been treated fairly extensively in theory $(16,47)$. Various forms of creep "1aws" have been proposed, and used in numerical modelling $(23,52,80,91)$. 


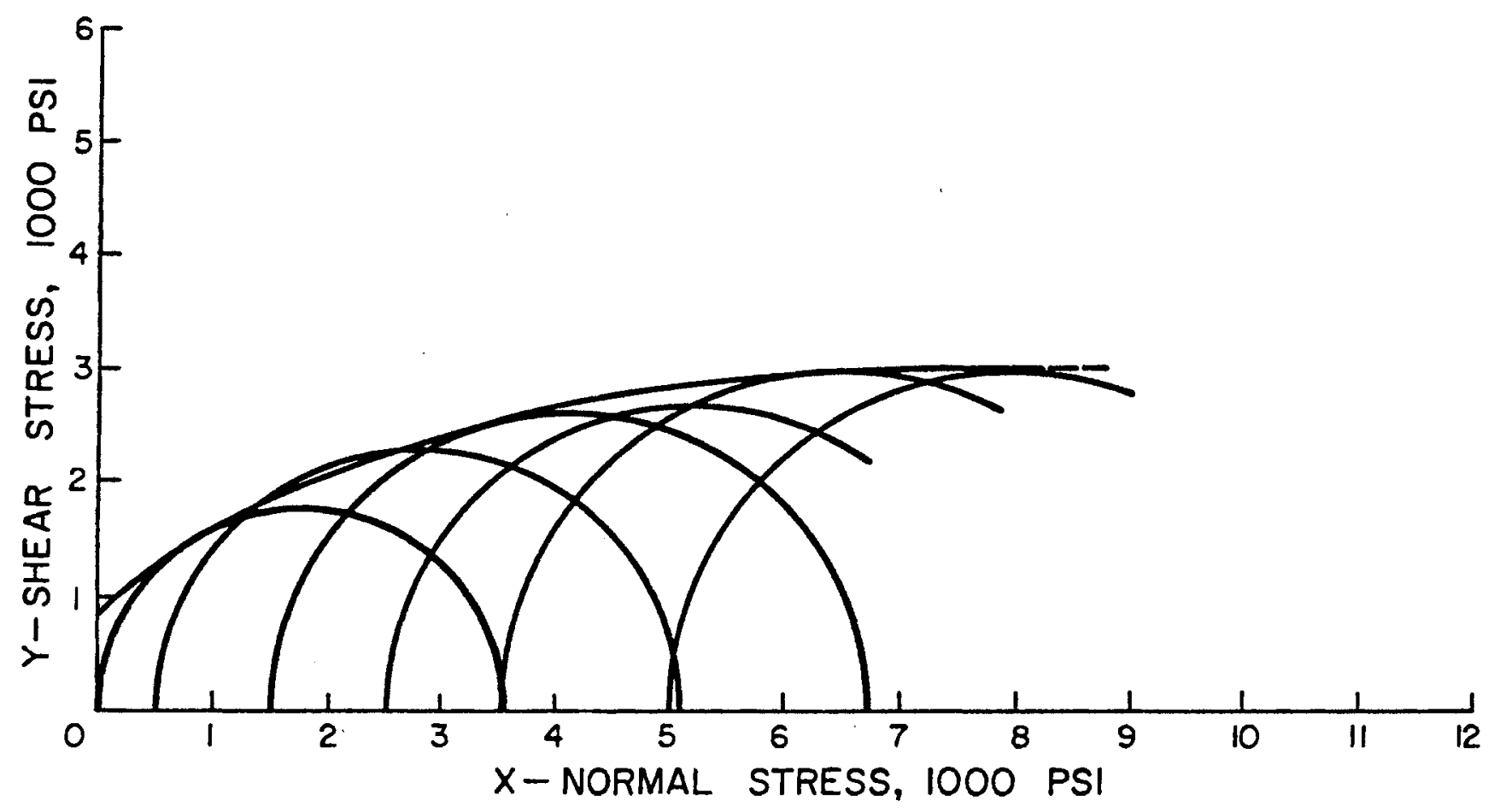

Fig. 4.5-3. "Strength" of Rock Salt at 2\% Deformation (After Reference 85). 


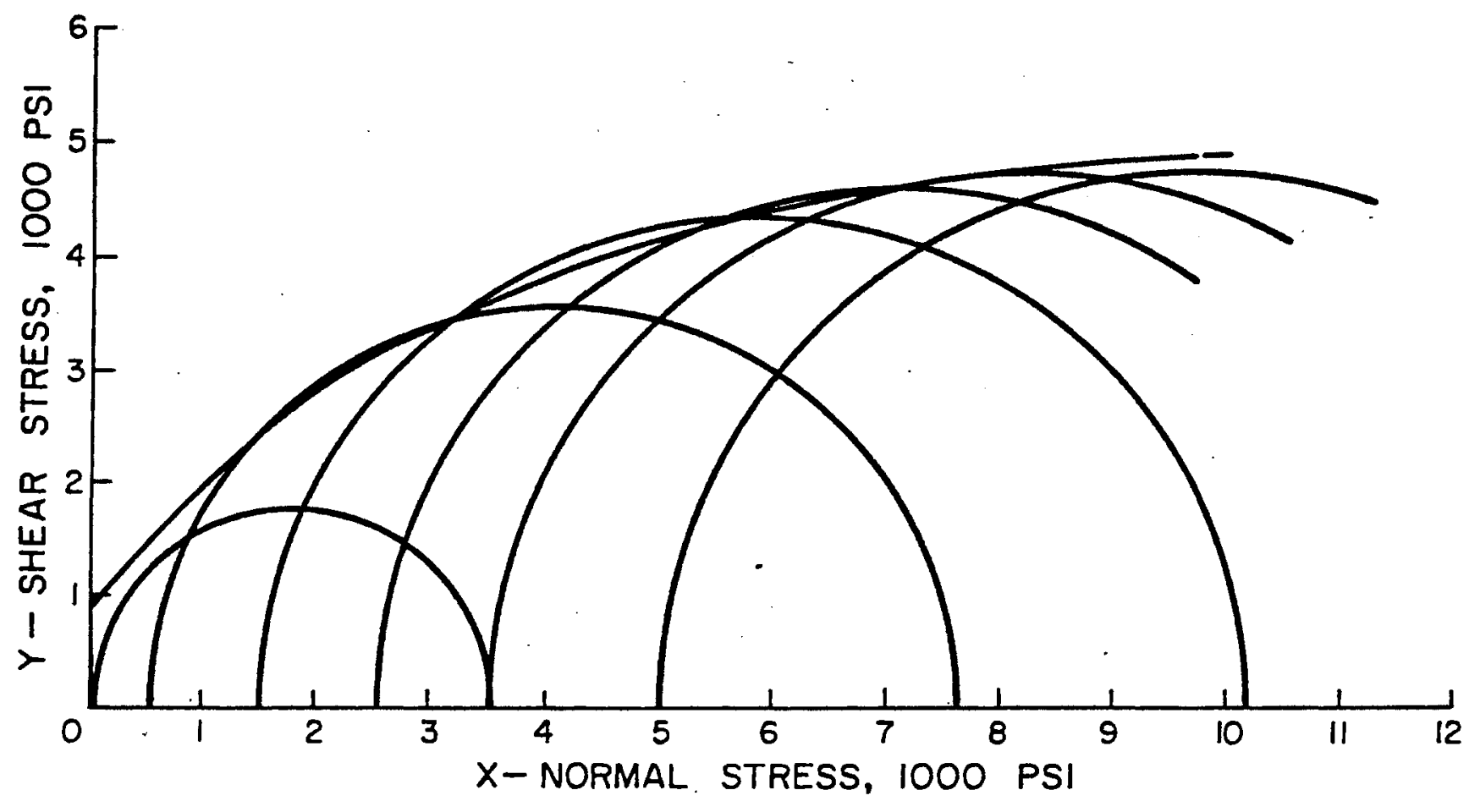

Fig. 4.5-4. "Strength" of Rock Salt at 10\% Deformation (After Reference 85). 
41.

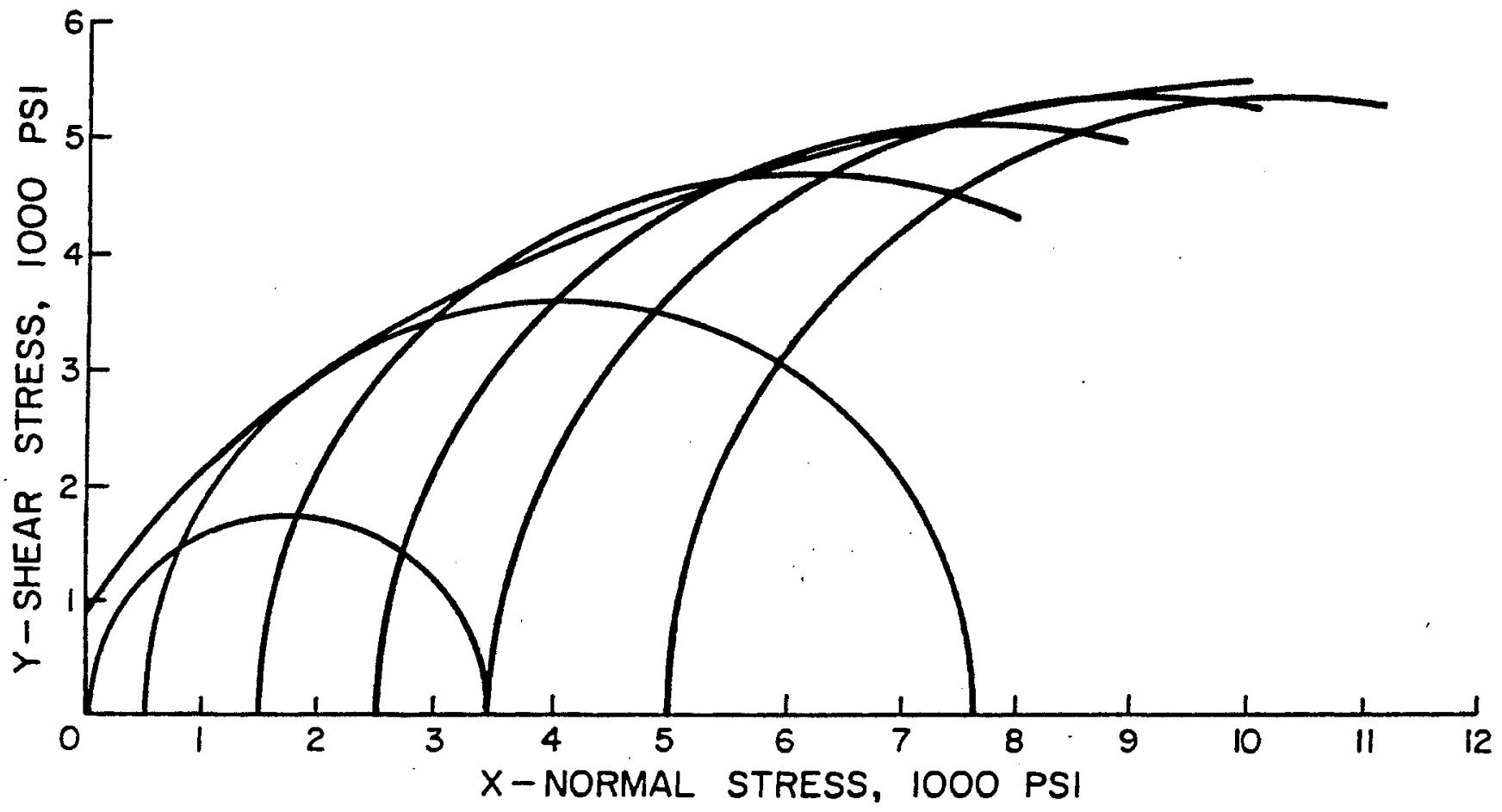

Fig. 4.5-5. "Strength" of Rock Salt at 20\% Deformation (After Reference 85). 
For example, creep, at some time $t$, can be expressed in matrix notation in the form,

$$
\frac{d\{\varepsilon\}_{C}}{d t}=[C C]\{\sigma\} \quad 4.5-4
$$

thus,

$$
\Delta\{\varepsilon\}_{C}[C C]\{\sigma\} \Delta t \quad 4.5-5
$$

Where [CC], the material creep "compliance" at time $t$, relates the vectors of incremental creep strain and the stress state over a time interval $\Delta t$. The size of $\Delta t$ is selected both on the basis of rates of change of significant parameters, e.g., stress, strain, configuration, and temperatures, and also on the basis of the stability of the numerical algorithm employed to model creep. The degree of stability usually is estimated with numerical experimentation in applications of working creep programs. As examples, creep behavior of laboratory test specimens can be modelled, or exact solutions simulating rock salt behavior.

Examples of particular creep laws can be noted relative to the form taken by the creep compliance matrix of Eq. 4.5-5. The argument of the creep compliance matrix has been represented by Fossum as a combination of the second invariant of the deviator stress, $\mathrm{J}_{2}$, and a strain measure (23). Fossum also notes that the state parameters should be functions of time, and that time cannot appear explicitly in any proper equation of state.

Heard employs an exponential form of creep law dependent upon absolute temperature and differential stress along with appropriate material parameters and the universal gas constant (37). 
Power law formulations have been used perhaps most frequently to represent time dependent rock salt behavior (16). Russell has noted that a power law formulation with a constant nonzero exponent for time cannot accommodate a steady-state creep phase (70). However Dwyer and Thoms have suggested that creep can be handied by a combination of traditional power law, in the transient phase, followed with a degenerate form wherein the time exponent is set to zero, in the steady state phase (22). This latter approach corresponds essentialiy to employing a spline fit in time for the material response of rock salt (18). Additional study is required, particularly with verification by in-situ tests, before a "best" creep model formulation is universally accepted. The analytical description of in-situ polycrystalline rock salt behavior, including creep rupture, currently requires a considerable amount of additional research.

There are little long-term creep data for thousands of hours available from laboratory experiments on domal salt because such tests obviously require considerable amounts of time, i.e., months. Most existing laboratory test data in geotechnical engineering are based on axial compression tests (either uniaxial or triaxial). This is appropriate since such tests "track" the loading environments of prime interest in the majority of geotechnical engineering applications. However, the principal phenomenon involved in time dependent cavern closure is best simulated with triaxial extension creep tests (58). For with reference to Fig. 4.5-6., the loading environment associated with creep closure of a storage cavern would be most nearly attained in the laboratory by tests on cylindrical specimens with axes normal to the cavern surface and 
$\left|\sigma_{3}\right|>\left|\sigma_{1}\right|$; where $\sigma_{3}$ and $\sigma_{1}$ represent geostatic stress and cavern pressure respectively $(11)$.
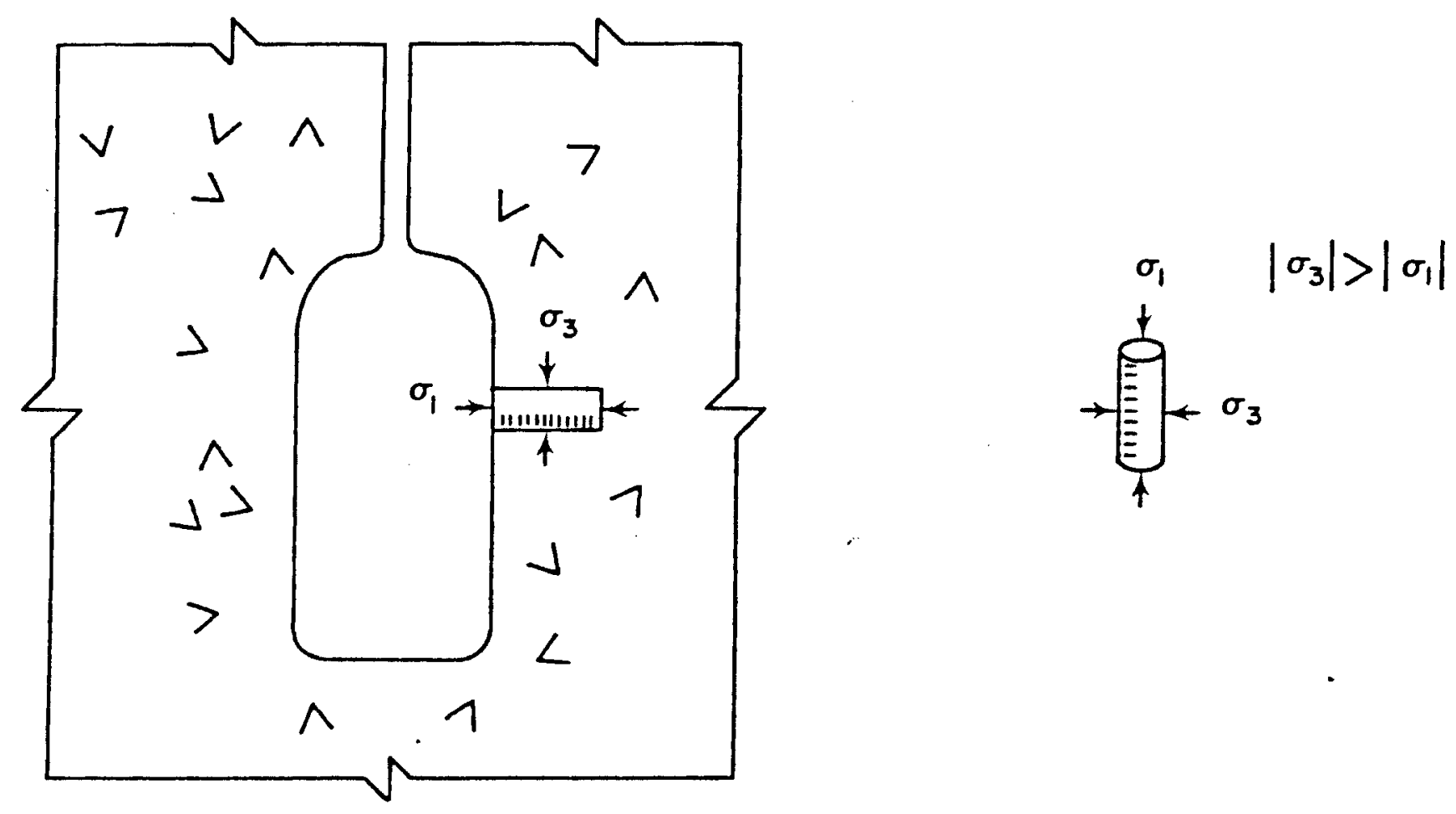

Fig. 4.5-6. In-Situ Representation by Triaxial Extension Test

Since test cylinders of salt are obtained from vertical holes it is necessary to assume material isotropy for data interpretation from triaxial extension tests relative to cavern creep closure in the horizontal direction. If sufficiently large cylinders can be obtained to machine horizontally oriented specimens without inducing scale effects, then this assumption is not necessary.

After a certain amount of strain has occurred in an extensional mode, the rock salt will "creep rupture". This phenomenon can be observed 
in south Louisiana salt mines where spalling of the walls occurs with the passage of time. As preventive maintenance measures, the mines are periodically "scaled" with a large machine with a metal pick that breaks off potential rock-fall material. In older and more shallow inactive mining levels, the spalling (creep rupture) phenomenon is particularly evident.

Figures $4.5-7$ and 8 . illustrate respectiveiy effects of creep closure and creep rupture in the upper level $(-540 \mathrm{ft}(-164.6))$ of the Weeks Island salt mine in South Louisiana. This mining level was opened around the turn of this century, and the power line pole of Fig. 4.5-7. was initially installed with some unknown clearance from the mine roof. Also, until the early $1950^{\prime}$ s, when this mine level was abandoned, the floor customarily was kept cleared of loose salt which spalled from piller corners (Fig. 4.5-8). Vertical creep closure of the mine opening broke over the power line pole, and creep rupture induced the pillar corner spalling with an accumulation of loose salt crystals on the floor. Less friable salt frequently ruptures away from mine piller corners in the form of essentialiy free standing columns, which eventualiy topple over.

In laboratory testing of rock, clearly visible failure due to creep rupture can be observed in triaxial extension creep tests (Fig. 4.5-9.), but not in conventional triaxial compression creep tests (Fig. 4.5-10.). This again points up the more appropriate loading environment of triaxial extension tests over compression tests for cavern closure studies.

CAES caverns will be subjected to typical daily and weekiy cycles of pressure (and temperature) variation. Thus the "fatigue limit" of the rock salt in the cavern walls will be of primary concern. As noted previously, the Huntorf CAES cycle will include cavern pressurization 
46.

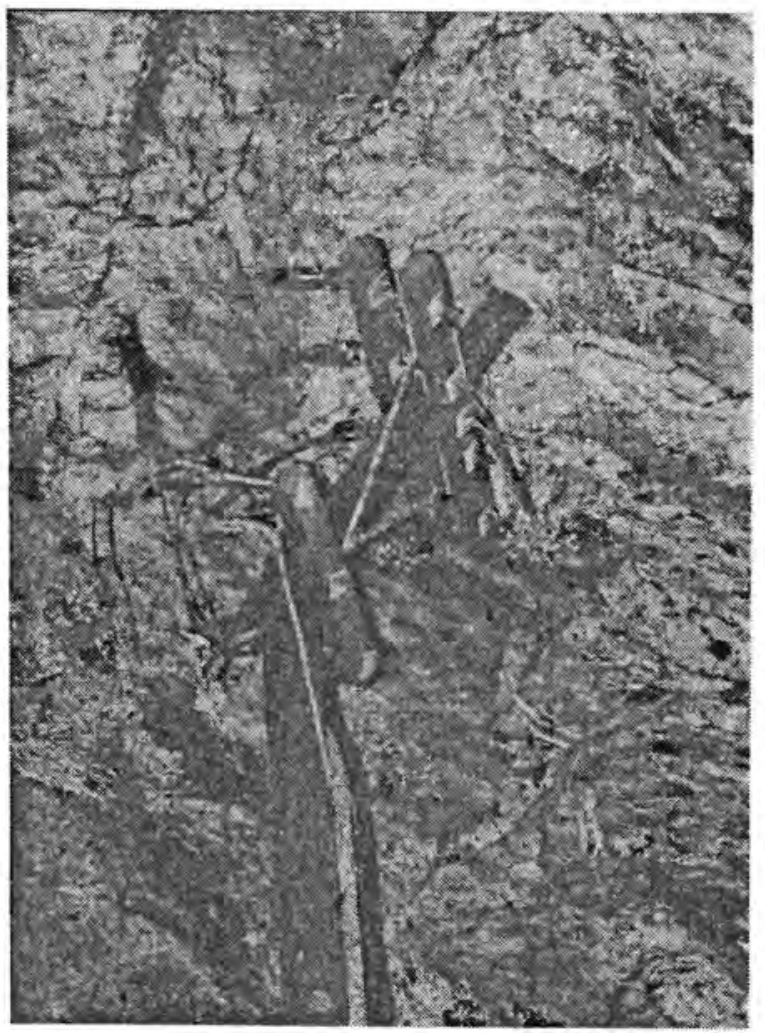

Fig. 4.5-7. Creep Closure Effect In Salt Mine

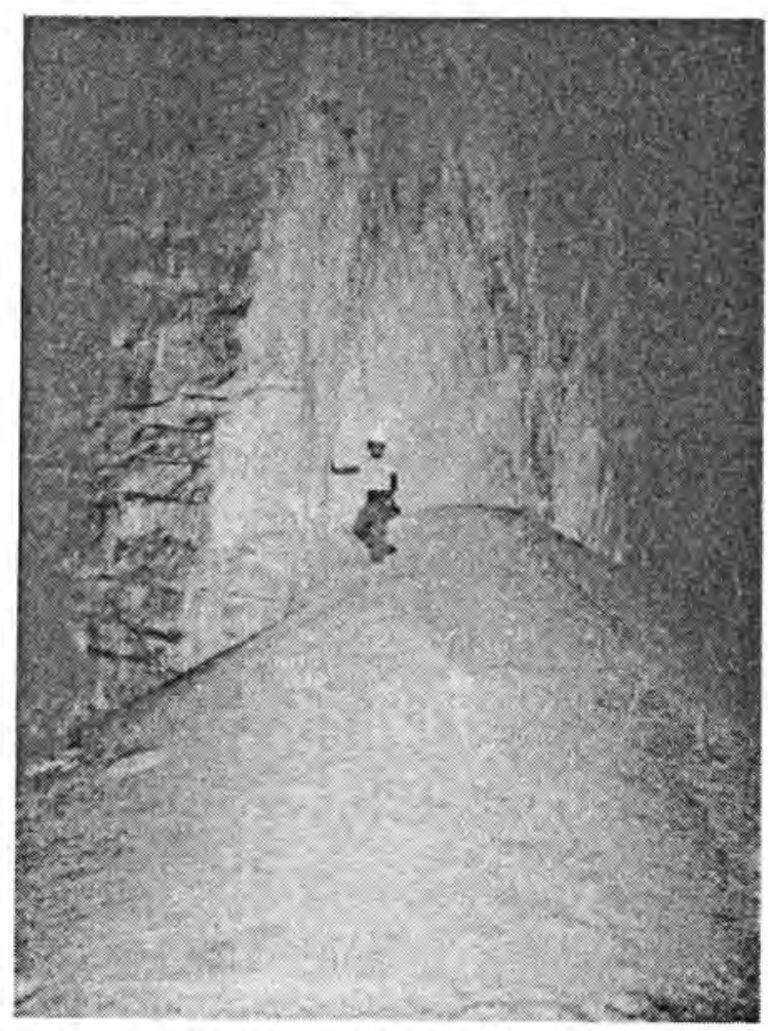

Fig. 4.5-8. Creep Rupture Effect At Corner of Salt Pillar 


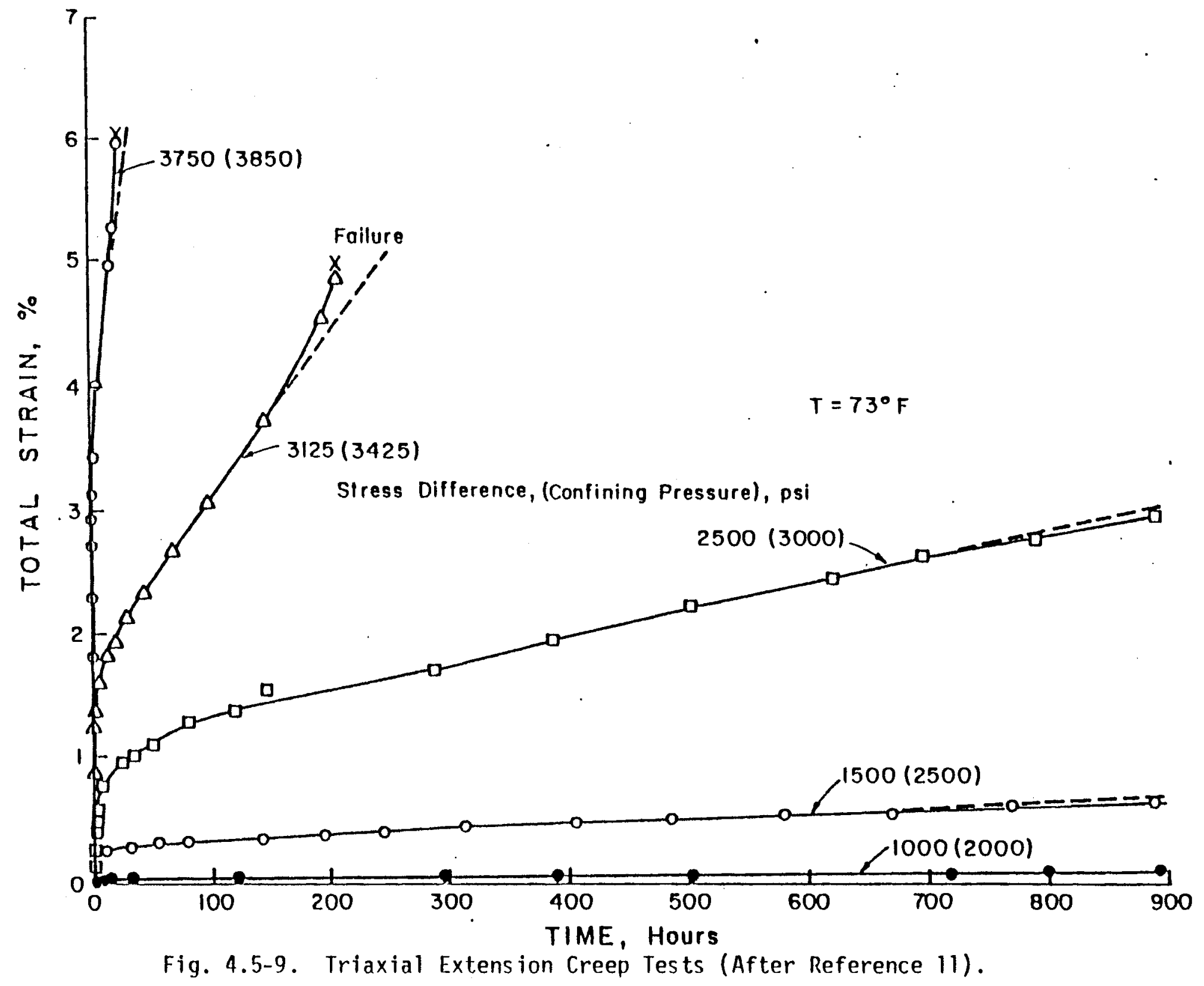




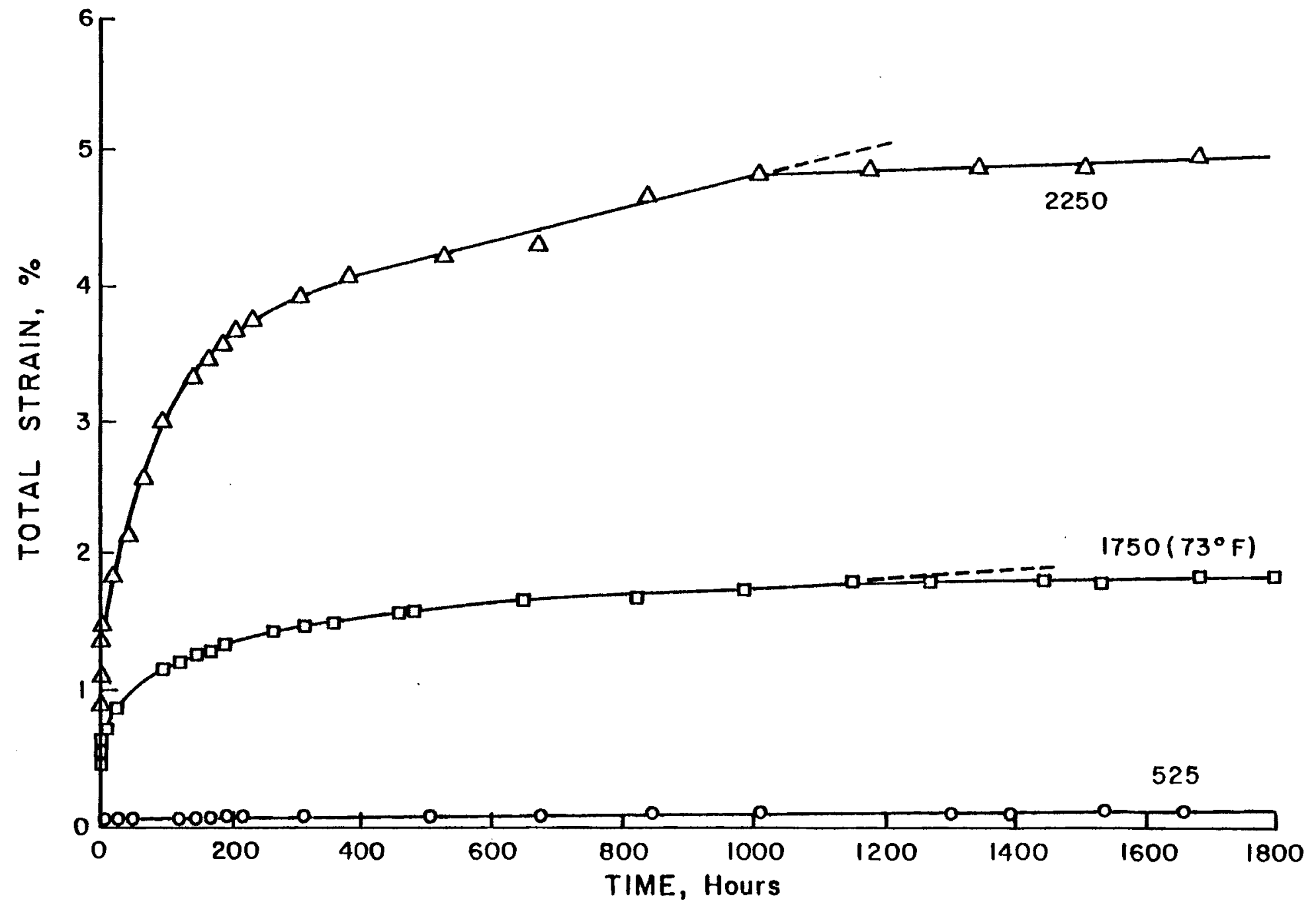

Fig. 4.5-10. Uniaxial Compression Creep Tests (After Reference 11). 
over eight hours to $70 \mathrm{~atm}$ followed by unloading over two hours to 50 atm. Other operating cycles obviously can be suggested. It should be noted that an upper limit has been placed on operating pressure within hydrocarbon storage caverns in Louisiana, i.e., "The maximum operating pressure (gauge) at the casing seat or chamber ceiling, whichever is the shallowest, shall not exceed .9 psi per foot of overburden" (75). This limiting pressure value was established mainiy on the basis of a large amount of experience of storage cavern operators in Gulf Coast salt domes. Typical daily and weekly cycles therefore probably will be bounded approximately by this value. Limiting pressure values must be kept in mind in setting up a cyclic effects ("fatigue") testing program. Some studies of low frequency fatigue cycles on other rocks have been made (35). Again, following the concepts developed for metals, the site-specific rock salt can be typified as possessing the ability to withstand a certain number of load cycles, under specified loading conditions, based on laboratory tests. After adequate study these test data can be interpreted in terms of years of service or engineering "life" of the cavern under operating cyclic loading conditions. If the "life" is not sufficient for the planned facility, then a different set of loading conditions or a site with "better" salt must be selected.

It is well known that rock salt behavior is strongly temperature dependent $(12,48,62)$. Thus all material "strength" properties determined in the laboratory should be qualified as typical for certain temperatures. In addition, the cyclic thermal stresses associated with the time varying temperature gradients in the cavern walls must be taken into account (38). 
In testing for cycles or low frequency fatigue effects associated with CAES, it is possible that the influence of temperature and stresses will be strongly coupled (89). Thus testing for explicit effects on rock salt due to pressure and/or temperature cycling alone may not be adequate for CAES studies. Therefore, simultaneous pressure and temperature cycles should be simulated in at least one phase of a laboratory or bench scale testing program to assess possible coupled fatigue effects. Furthermore, the surface of the salt specimens should be exposed to air with various degrees of water content in order to establish levels of possible deterioration in the exposed crystal fabric.

other material properties affecting cavern stability considerations include unit weight, permeability, heat capacity, conductivity and thermal diffusivity, moisture content, and compressibility (bulk modulus) of the salt and other geologic materials. The unit weight of salt obviously influences the stress state in the cavern walls. Further, unit weight of salt possibly may be useful as an index number to characterize salt variability, including anhydrite content, within a dome or domes (66). Heat transfer parameters obviously will enter into the analysis of the time dependent temperature field surrounding a storage cavern.

\subsection{Loading Parameters}

Loading parameters affecting cavern stability in salt domes are discussed individually in the following paragraphs.

Perhaps the most significant long term loading parameter is the pressure difference, $p d$; i.e., $p d=g-p$, where $g$ corresponds to the magnitude of geostatic stress in surrounding salt due to overburden, and $p$ corresponds to the magnitude of cavern pressure (68). The paramater $g$ 
51.

is a function of depth and unit weight of overburden material. Obert determined the geostatic stress state in Gulf Coast domal salt, at some distance from a mined opening, to be hydrostatic in character and equal in magnitude to overburden effects, i.e., $g=\int$ wdf, with $w=$ unit weight at depth $h(61)$. This determination was made using the overcoring method which requires assumptions about material behavior. The material behavior of rock salt is complicated; and thus, other methods, e.g., flat jacks, also should be employed for stress determination in domes. The magnitude of cavern pressure $p$ is specified, for a noncompensated cavern, simply by gauge pressure at the "wellhead" of the surface facility. The pressure along with the geometrical configuration of a cavern and material properties of salt are primary input data for analyzing the associated stress and displacement fields and subsequently the stability of storage caverns in salt domes. A "first cut" analysis of stress distribution around CAES caverns can be obtained with widely available axisymmetric finite element programs and assumed linear "effective reaction" moduli for material response. This analysis then can be used as a basis for selecting loadings for a laboratory testing program on rock salt response under simulated CAES conditions. Effective reaction moduli can be estimated, for example, from Fig. 4.5-2., and anticipated loading histories and environments.

It is relatively well known that salt behaves as an "elastic" brittlelike material if loaded (or unloaded) at a rapid rate $(20,21,62)$. In storage caverns the pressure unloading rate, $\frac{d p}{d t}=\dot{p}$, must be limited as roof falls apparently have been caused by rapid pressure drops. The "transition" loading (unloading) rate, above which rock salt behaves as a brittle material, has not been studied carefully to the knowledge of 
these authors. The transition rate should be established as part of a more complete investigation of long term CAES cavern stability, and could be included in the material properties investigations described in the previous subsection.

The temperature and rates of temperature change with time of the fluid (air and possibly brine) used as the pumping media for CAES caverns in salt domes are significant loading parameters since rock salt becomes more plastic with higher temperatures. Also, as previously noted, time dependent thermal stresses will be incurred in the cavern walls because of varying temperatures (38).

Lomenick performed a series of laboratory experiments in which he studied effects of elevated temperatures and different loads on the creep behavior of rock salt model mine pillars. Based on his model studies, he reported "temperature is the single most important parameter that affects cavity closure in salt mines" $(48$, p.95). His empirical relation for vertical creep rate of pillar models utilizes temperature $\left({ }^{\circ} \mathrm{K}\right)$ with an exponent of 9.5. He further concludes, "at $200^{\circ} \mathrm{C}$ severe structural stability problems will occur in subsurface salt excavations, even at superincumbent loads as low as 2000 psi" (p. 41).

From Lomenick's results, an upper bound on salt temperature around storage cavities should be less than $200^{\circ} \mathrm{C}$. However, an even lower upper limit for temperature is desirable for CAES reservoirs where relatively stable storage volumes are required for approximately 35 years. Thus a maximum salt temperature of $80^{\circ} \mathrm{C}$ in the reservoir wall is postulated as an upper bound for CAES. It should be noted that maximum air temperatures could be higher during injection periods. Rock salt, as a geologic material, has relatively large values of heat capacity and thermal 
conductivity (15). Furthermore air, with relatively low heat capacity, will be injected and withdrawn into a large CAES reservoir away from the immediately surrounding rock salt "walls". Heat from the air will be transferred into the salt by convection, which can be analyzed with an appropriate film coefficient which should incorporate effects of seasonal variations in condensate on the cavern walls. Thermal "shocks", or even significant variations in temperature, probably will not be experienced by the salt. Instead, salt temperatures probably will be close to mean values of operating CAES cycles even relatively close to the cavern wall surfaces; and will decay rapidly to ambient temperatures in the salt stock away from the caverns.

It is probable that cyclic temperature and pressure loadings may couple to accelerate deleterious effects within the salt around CAES caverns. Again, to the authors' knowledge, no work has been reported on long-term cyclic loading effects on rock salt behavior; although such studies may be underway.

In conclusion of this section, factors potentially affecting stability of CAES caverns have been discussed in some detail. Determination of material properties appropriate for analysis of CAES caverns will require further study. A number of significant effects have not been studied (or at least reported) on a rational engineering basis.

In the next two sections, a methodology for developing quantitative and site-specific long-term stability criteria for CAES caverns will be proposed along with a plan for implementation of the criteria. The reader will note that a number of potentially significant parameters in the proposed criteria will require further study. 


\section{DEVELOPMENT OF SITE-SPECIFIC STABILITY CRITERIA}

The development of a complete set of quantitative site-specific stability criteria requires: (1) the gathering of site-specific technical data; (2) appropriate analyses which will yield predictive quantitative results; and ultimately, (3) the verification of criteria by agreement between predicted and monitored performance.

In this section a brief review is presented of data gathering methods which appear particularly appropriate for development of quantitative CAES stability criteria. Then a three-stage format is proposed for developing site-specific criteria; each stage incorporates the three requirements listed previously for criteria development.

\subsection{Testing Methods For Data Gathering}

Geotechnical stability criteria generally are based on corroborating laboratory and field data collected from a significant number of studies. As noted previously, only limited laboratory and field data currently exists for the time dependent behavior of rock salt. Furthermore, many of the laboratory tests performed were conventional compression tests which more nearly simulated the vertical shortening of pillars in salt mines, as contrasted to the triaxial extension associated with creep closure in a direction normal to a mined opening in rock salt.

Boresi and Deere (11) considered triaxial extension tests to be the most meaningful for gathering data relative to creep closure of a cavity in rock salt. Furthermore they concluded that "the real problem is not so much one of strength but one involving the rate and magnitude of creep of the rock salt into the cavity." 
Some workers place little confidence in data gathered from laboratory testing of rock salt cores (8). However, such test data should be regarded as only one piece of information to be used in establishing complete stability criteria as previously discussed. Appropriate laboratory testing, at the very least, should yield index parameters to permit comparison of rock salt specimens from different sites. It is essential that the rock salt specimens be taken with minimum disturbance during coring. And, ideally, comparisons should be made between salt specimens taken at the same depth so as to more nearly equalize effects of unloading from initial geostatic stress states.

Tests on borehole walls in rock salt have been proposed by several workers $(13,74,83)$, and a number of instruments have been developed for this purpose $(26,30,54,73)$. These instruments typically extend plates or inflatable packers against the borehole walls for load application, and simultaneously monitor resulting displacements with differential voltage transformers (LVDT). Also, borehole "flatjacks" may be employed for obtaining changes in stress states without recourse to assumptions of linear material behavior, which is particularly appropriate for strongly time dependent rock salt. Appropriate borehole testing appears highly viable for collecting more realistic data on time dependent in-situ behavior of rock salt.

Other information exists on cavern behavior in rock salt in association with field testing and experiences $(4,21,68)$. For example, if a liquid storage cavern is "shut in", then the wellhead pressure will rise above atmospheric pressure due to creep closure into the cavern. If a surface valve is opened, a measurable amount of liquid will be expelled 
and the wellhead pressure will drop to atmospheric pressure after some time. Taking into account the liquid volume displaced, the drop in wellhead pressure, and the compressibility of the liquid involved, an estimate of the bulk modulus of rock salt at a site under in-situ conditions can be obtained. Also, some measure of the creep behavior of salt can be obtained from borehole tests. Obviously, these field techniques become complicated if gas is present in the salt stock.

\subsection{Development of Criteria In Stages}

Development of site-specific stability criteria for CAES caverns should encompass three stages: (1) Development of laboratory and bench scale testing, (2) pilot cavern or borehole testing, and (3) prototype construction, testing, and operation. In all three stages data should be collected and "fed back" via numerical modelling to check agreement between predicted and measured rock salt behavior associated with cavern operation. If agreement is not initially attained, the analysis (numerical models) should be updated to track more closely the most recent monitored performance of either laboratory specimen, pilot cavern, or prototype facility. This concept was essentially initiated by Terzaghi for the early analyses programs accompanying construction of geotechnical engineering projects (79), and appears particularly appropriate in formulating and eventually verifying site-specific stability criteria in stages for CAES caverns.

Figures 5.2-1. through 3 . depict schematically the three stages in developing stability criteria for CAES caverns. The reader will note that the work plan is similar for each stage, and repeats the previously described analysis concept due to Terzaghi. Stage (3) is almost identical 


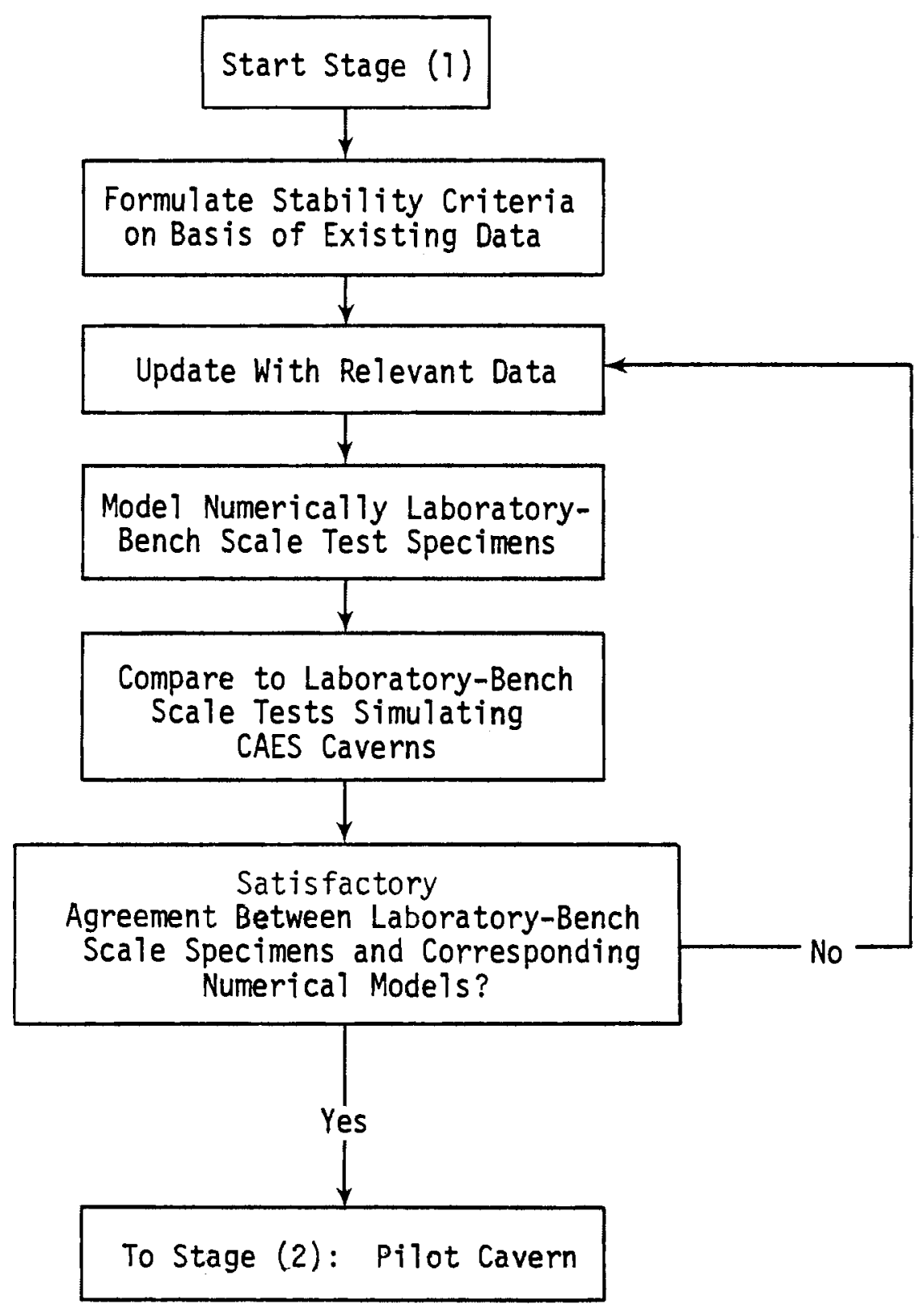

Fig. 5.2-1. Stage (1): Laboratory-Bench Scale Testing 


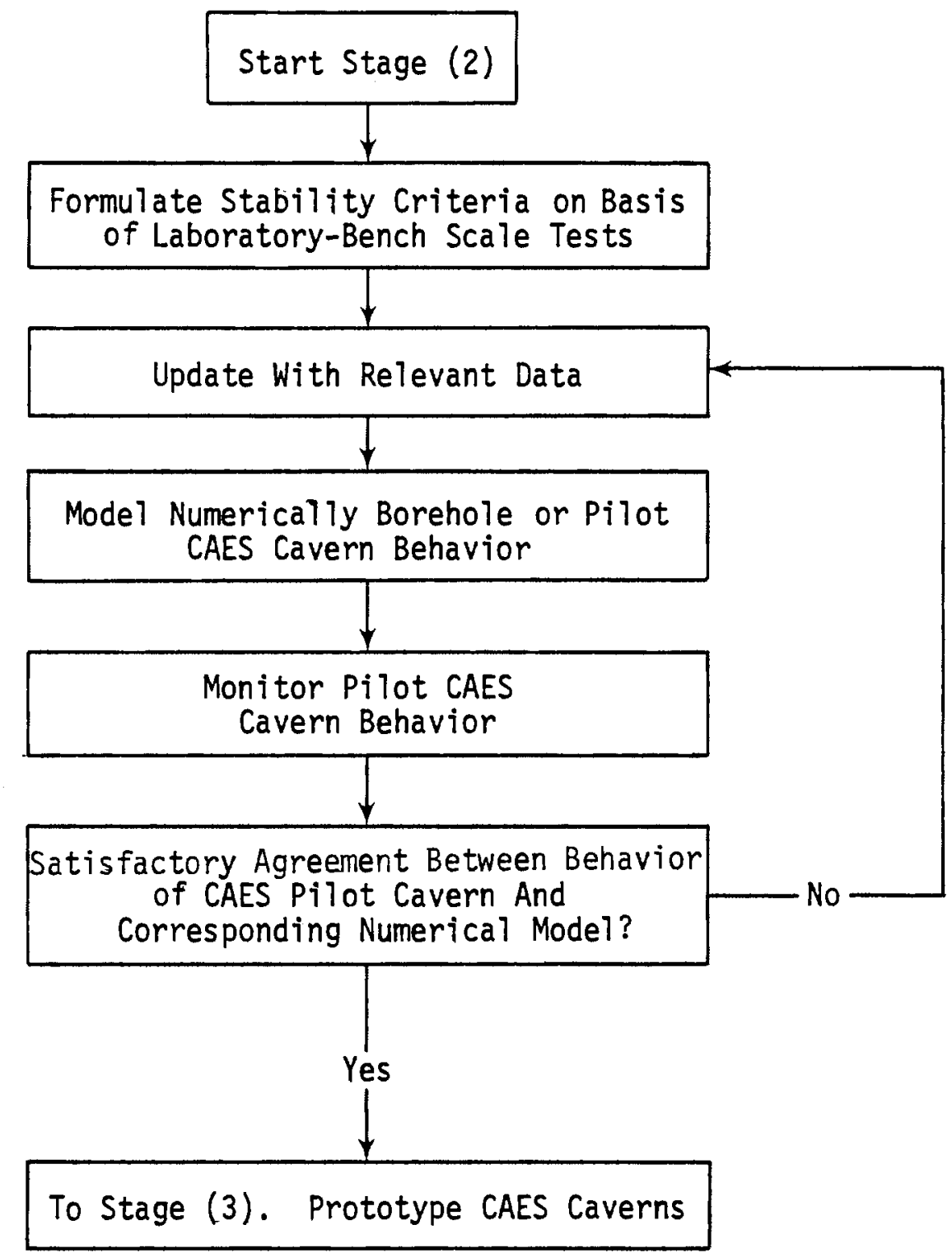

Fig. 5.2-2. Stage (2): Pilot CAES Cavern Monitoring 


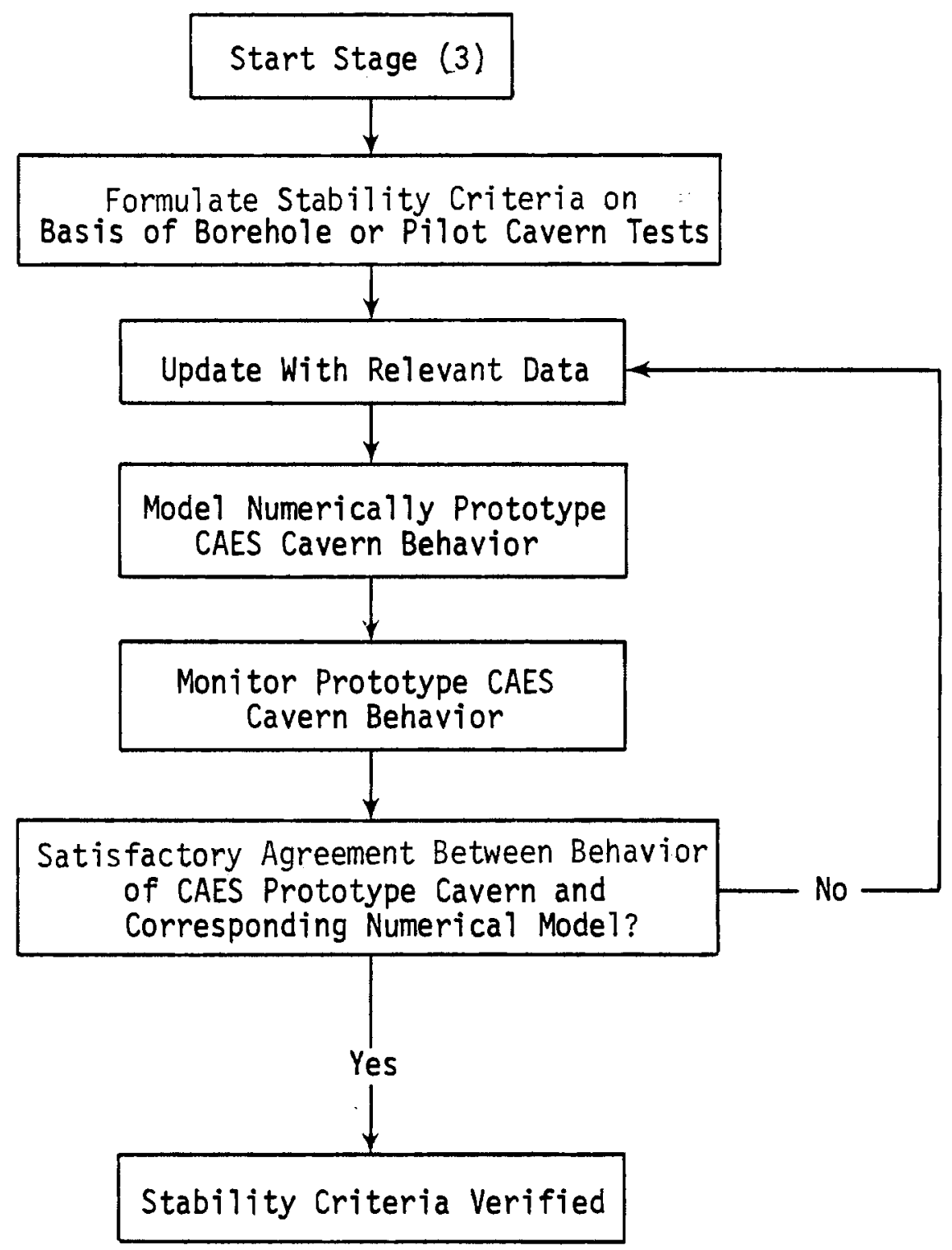

Fig. 5.2-3. Stage (3): Prototype Monitoring And Criteria Verification 
to stage (2), but with "prototype" replacing "pilot"; and final verification of prototype cavern stability criteria as the end goal. Since finite element methods have become the principal analytical aid in geotechnical projects, the specific term "numerically model" has replaced the more general term "analyze".

Data collection via appropriate instrumentation monitoring systems is a major component in verification of stability criteria in the pilotprototype stages (2) and (3). As noted previously, a laser ranging device has been developed to monitor distances in pressurized gas filled caverns under operating conditions (59). More sensitive displacement monitoring methods, e.g., photogrammetry, may prove useful in monitoring small (pilot) CAES caverns. Great advances also have been attained recently in development of sensitive instrumentation that can be used to monitor minute magnitudes of surface subsidence, horizontal and rotational displacements, and fault movement $(5,40)$. In addition, the monitoring of microseismic emissions currently is being used in a number of mines to detect impending rock bursts, and also to evaluate stability of natural gas storage reservoirs $(33,34)$. Eventual application of microseismic monitoring methods will utilize site specific and in-situ seismic velocity surveys of salt domes (81).

Thoms, et.al., (1977) have described and currently are emplacing field instrumentation systems over two salt domes in north Louisiana to monitor possible minute tectonic movements (83). The complete monitoring study incorporates complementary numerical models of the geomechanical systems associated with the salt domes. The field monitoring instrumentation includes precise levelling, tiltmeters, strainmeters, microseismic 
monitoring and laser ranging. A schematic of the complementary components of this dome movement monitoring study is depicted in Fig. 5.2-4. and the interaction of efforts involved in data interpretation is depicted in Fig. 5.2-5. Data interpretation requires knowledge of the geologic features typically associated with salt domes. For example, growth faults and thinning of overlying formations (due to relative elevation of the dome during sedimentation phases) will affect material characteristics on a global scale.

The field monitoring of a CAES cavern pilot or a prototype system could be accomplished by a combination of cavern laser ranging, strainmeters, tiltmeters, precise levelling, and microseismic monitoring methods. In addition, slope indicator devices in a borehole adjacent to the cavern could be employed (17). Since the configuration of a CAES cavern would be well known and compact, its monitoring and complementary numerical modelling should be relatively straightforward.

A complete initial prototype CAES cavern system study would form a substantial basis for design and development of additional CAES systems. In each case however, some site specific exceptions to experiences encountered during the initial study should be anticipated. 


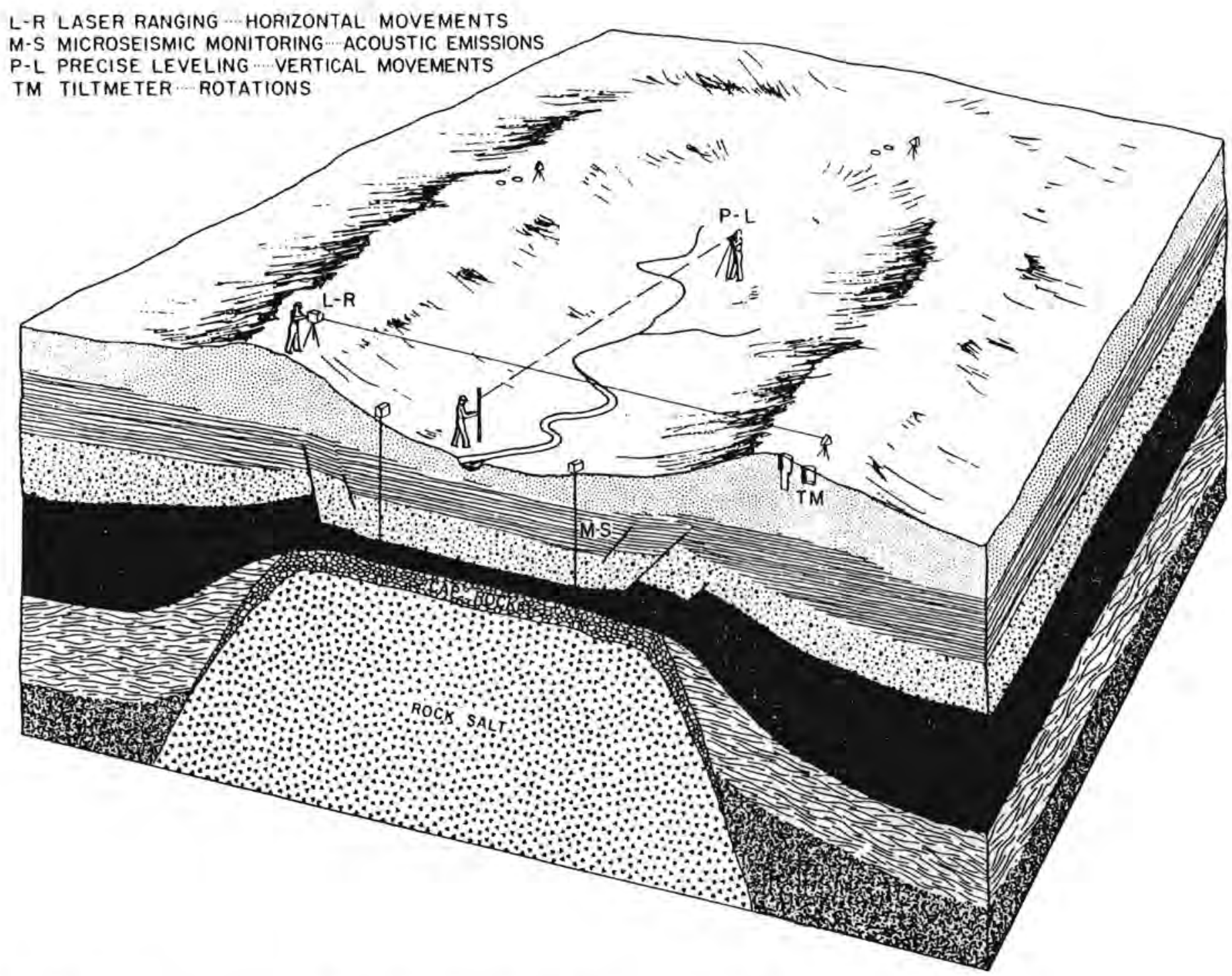

Fig. 5.2-4. Components of Dome Monitoring Instrumentation System. (After Reference 83). 
63.

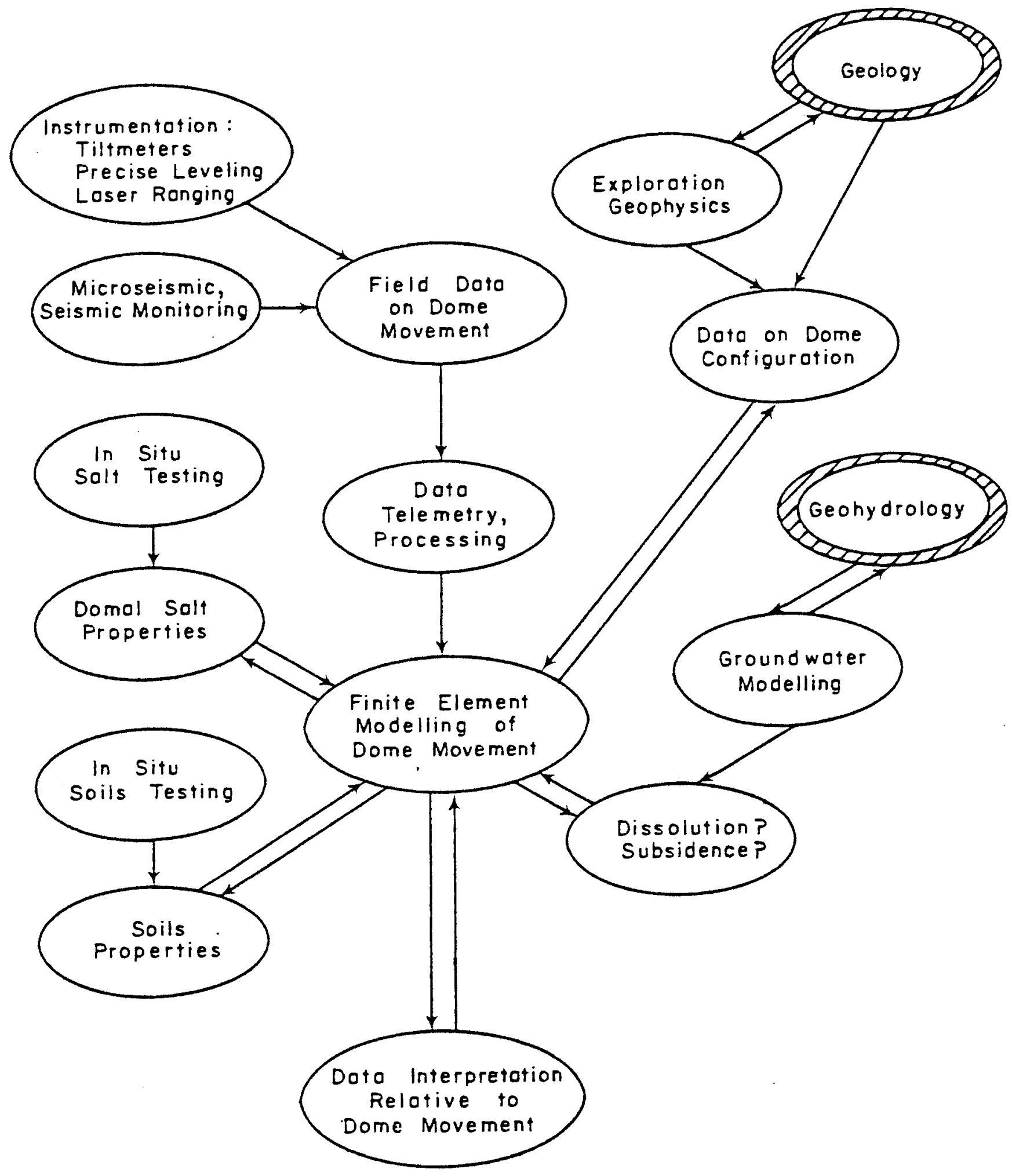

Fig. 5.2-5. Interaction of Efforts Relative to Monitoring Current Rates of Dome Movement (Reference 83). 


\section{IMPLEMENTATION OF STABILITY CRITERIA FOR CAES CAVERNS}

In this section the implementation of criteria enhancing longterm stability of CAES caverns will be proposed in a three phase format. The three phases generally follow a work plan sequence by which a CAES facility could be established and made operational. Frequent reference will be made to significant factors as previously described in Section 4. The three phases of stability criteria implementation are associated respectively with: (1) site selection, (2) cavern system design, and (3) facility operation. In this report, as previously noted, "stability" of storage caverns in rock salt implies the extent to which an acceptable amount of cavern storage volume can be utilized with routine maintenance for a specified time interval.

\subsection{Phase (1): Site Selection}

Stability criteria to be considered during phase (1), site selection of a potential host CAES salt dome, include: (1) The dome preferably should have a utilization history which is well known and relatively free of extensive sulphur or brine mining. (2) Geological, geophysical, and corehole investigations should reveal desirable megascopic features which include a homogeneous and isotropic salt stock relatively free of inclusions of sediment beds, lenses, or boudins of anhydrite and brine and gas (possibly $\mathrm{CO}_{2}, \mathrm{H}_{2} \mathrm{~S}, \mathrm{~N}_{2}$, and/or methane). Furthermore, the caprocksalt interface preferably should be a solid contact. That is, domes with a highly permeable and vuggy caprock and intervening seam of porous anhydrite sand at the contact zone should be avoided if possible. The same investigations employed to establish megascopic features also 
would reveal the geometrical configuration of the dome. Suitable salt stock should be available for CAES caverns (with maximum operating pressure of 100 bars) at depths ranging from approximately 2000 to 5000 feet $(609.6$ to $1524.0 \mathrm{~m})$.

The required diameter and depth of the salt stock will be determined by the size, geometry and orientation of the cavern system planned for a particular facility. Horizontal dimensions, as depicted previously in Fig. 4.4-2., include a minimum salt thickness or wall, $W$, between caverns. Cavern diameter, $D$, will be based on a combination of requirements generally including specified volume for a particular CAES facility and stability concerns as described in this report. A volumetric extent of salt must be available to accommodate the cavern system in three dimensions and to provide a protective zone of minimum thickness, $B$. The thickness, $B$, is measured along lines of shortest distance between the cavern walls and dome surface (or other cavern systems within the dome).

If a site specific testing program is not available in the early stages of site selection and preliminary design, it is obvious that a conservative estimate of the required cavern spacing and boundary zone would have to suffice. Estimates can be based in part on dimensions used for hydrocarbon storage caverns and the CAES facility at Neuenhuntorf, as noted previously in this report.

\subsection{Phase (2): Cavern System Design.}

Stability criteria associated with a cavern system design are based mainly on principles of rock mechanics. Rock mechanics, as used in this report, includes in situ tests and observations in salt mines, 
66.

laboratory and bench-scale testing programs, and interpretative numerical modelling.

Using material properties as described in Section 4., the finite element method (FEM) can be used to analyze stability of a proposed cavern system. The FEM has become the principal numerical-analytical technique in geotechnical engineering because of the ease with which spatial representations can be achieved for nonhomogeneous and nonlinear properties and for realistic configurations of geologic media. Obviously the value of the analysis will depend heavily upon the fidelity of the parameters used to represent the in-situ behavior of rock salt subjected to the loading cycles of CAES operations. Also, empirical methods (physical models) can be used to analyze CAES cavern stability; these were used in fact to analyze the caverns in the first operational CAES facility near Neuenhuntorf, West Germany (personal communication, H. Lorenzon, KBB engineer, March, 1978). Detailed descriptions of physical modelling methods for storage cavern systems and associated anatyses have been presented by Dryer $(20,21)$.

The great advantage of the numerical modelling approach, when fully verified, is the ease with which parametric studies, including sensitivity analyses can be performed. For example, different cavern configurations can be studied with numerical experimentation to determine the stability sensitivity to a range of height-to-diameter ratios for a given average depth. Eventually all cavern stability analyses will rely heavity on numerical modelling methods in conjunction (aiways) with good engineering judgment. 
Thus, a second group of criteria for CAES caverns should include an initial finite element analys is of time independent stability (or instability), and a time dependent analysis of creep closure and rupture for proposed design configurations, including roofs, walls, and/or floors. The numerical machinery of the finite element method (FEM) exists to perform these analyses. However, field data do not yet exist to verify the current status or "best" approach for analyses by FEM, particularly with regard to representing time dependent material properties such as creep closure and rupture and fatigue (or progressive failure) sensitivity to cyclic pressure, temperature, and moisture environments. Basically, cavern stability criteria imply that limits on stress fields and displacements around caverns must be imposed. The FEM is an important aid in establishing these limits.

Should a proposed cavern system configuration be analyzed as unstable, the proposed caverns then may be altered so as to take on more nearly spherical (and therefore more stable) shapes. In addition, a more nearly homogeneous stress state would be attained thereby in the surrounding salt. Loading parameters, as described in the next subsection, also may be varied to increase cavern stability as indicated by numerical modelling.

\subsection{Phase (3): Facility Operations.}

An example CAES cycle with a period of one week is depicted in Fig. 6.3-1. (86). A possible atypical cycle would include an abrupt pressure drop due to a facility malfunction or human error. Such effects cannot be readily incorporated into stability criteria except to note they 
should be prevented with appropriate back-up safety procedures and equipment (check valves) in the facility design.

An important feature not included in Fig. 6.2-1. is a controlled drop in pressure and temperature during a cavern depressurization "shutdown". Occasional shutdowns may be required to inspect and maintain the casing and valves connecting the CAES caverns to the surface facility.

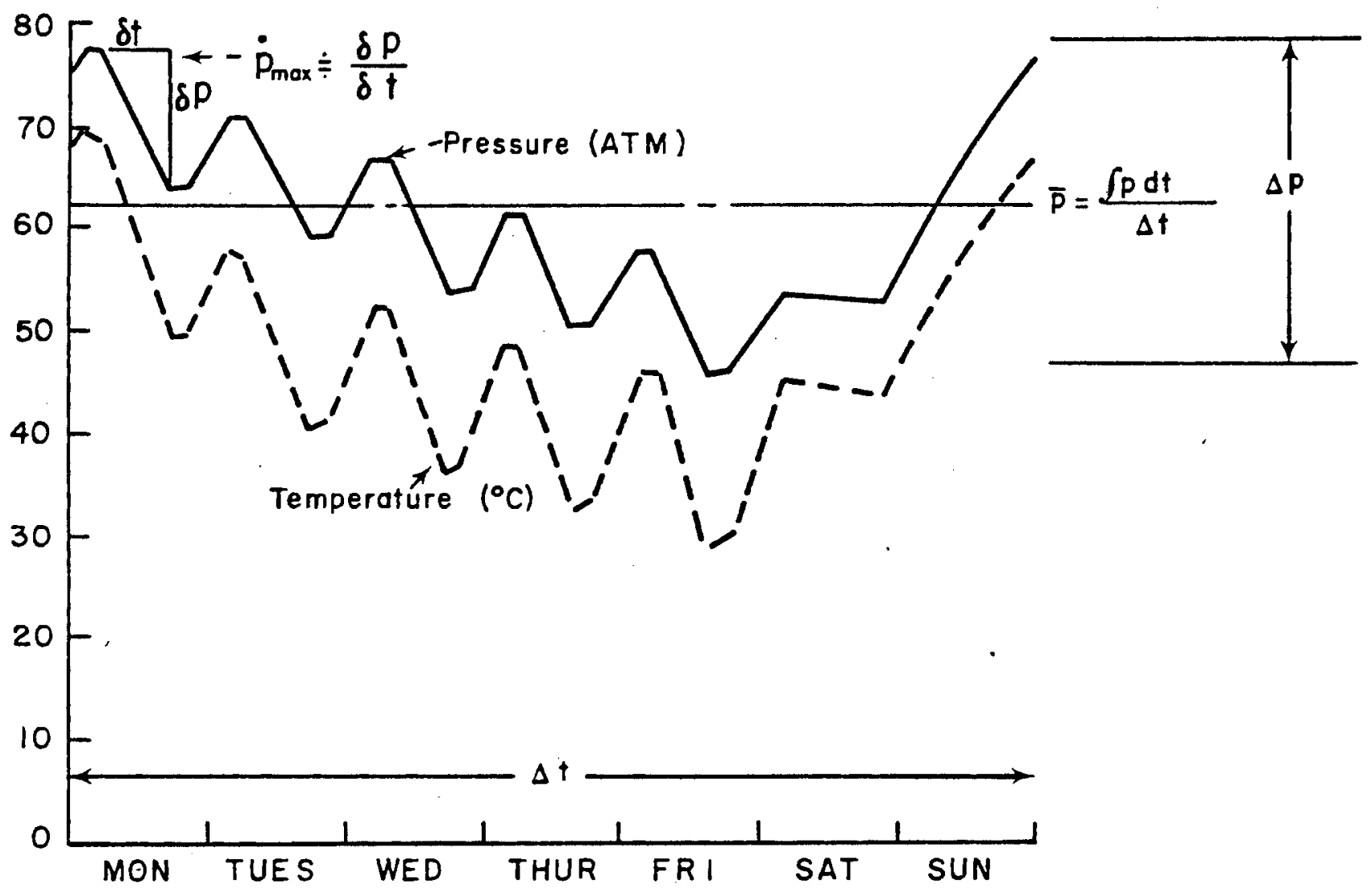

Fig. 6.3-1. Week1y Cycle of Pressure and Temperatures in CAES Cavern (Modified from Reference 86 ). 
Stability criteria associated directly with the operating program phase of CAES caverns will include limits on: mean pressure, $\bar{p}=\frac{s p d t}{\Delta t}$, pressure amplitude, $\Delta p$, over the period $\Delta t$ of a weekly cycle; and maximum pressure unloading rate, $\frac{\delta p}{\delta t}$ during a daily cycle. Similar limits on temperature likewise must be considered, although temperature will be strongly coupled to pressure variations. Progressive failure criteria associated with cyclic loading will imply limits generally on the number of cycles, $n$, and therefore on the lifetime of a particular configuration of cavern system subjected to a specified loading program in a site specific salt dome.

\subsection{Schematics for Stability Criteria Implementation}

Figures 6.4-1. through 3. depict the implementation of long-term cavern stability criteria discussed in the preceeding subsections. Essentially the figures represent the utilization of criteria applicable to the three phases of CAES caverns: (1) site selection, (2) design, and (3) operation. The "Apply Stability Criteria" or "test" box at the bottom of each figure requires unanimous "yes" answers to satisfy the respective phase criteria. 


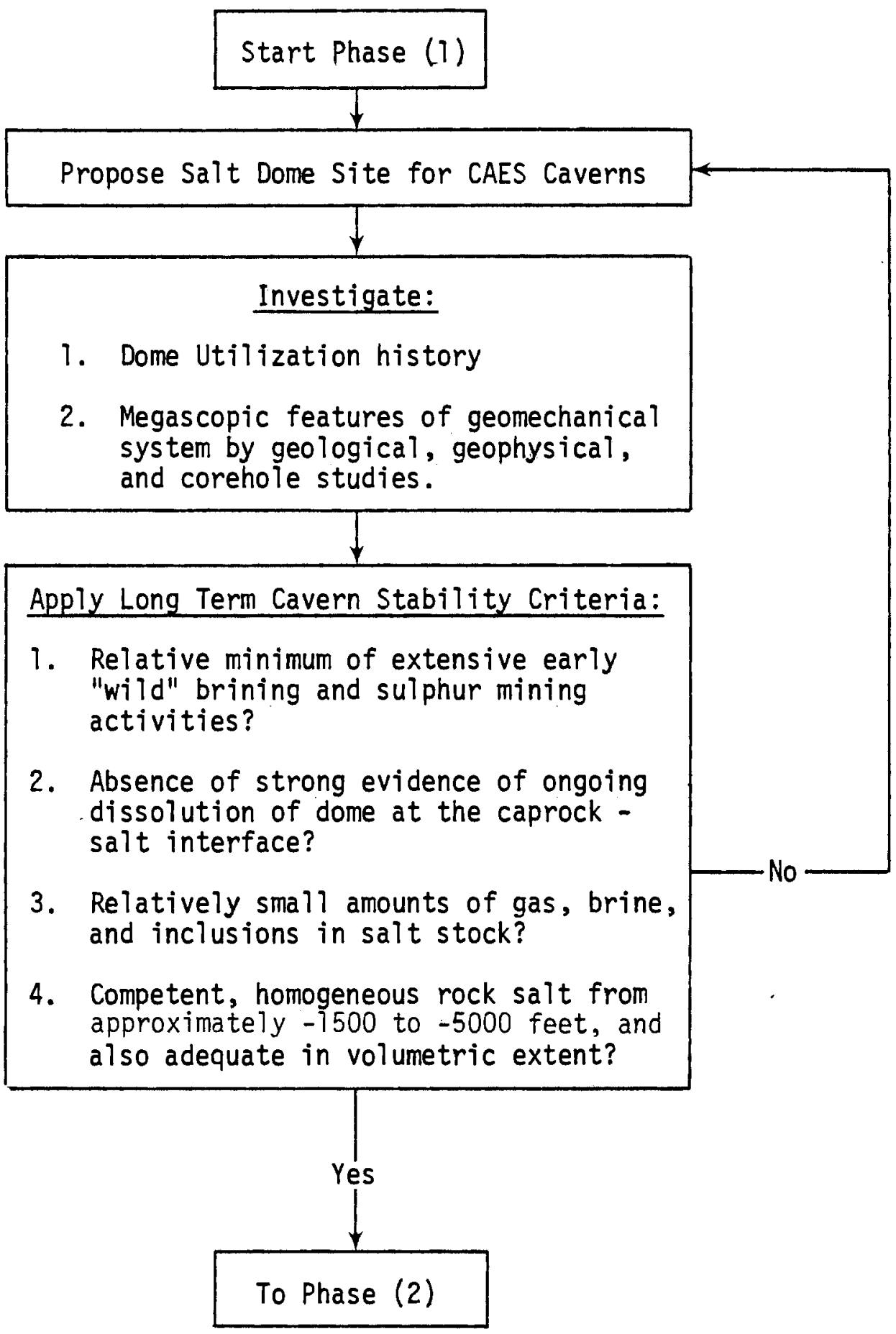

Fig. 6.4-1. Phase (1): Implementation of Stability Criteria in Site Selection 


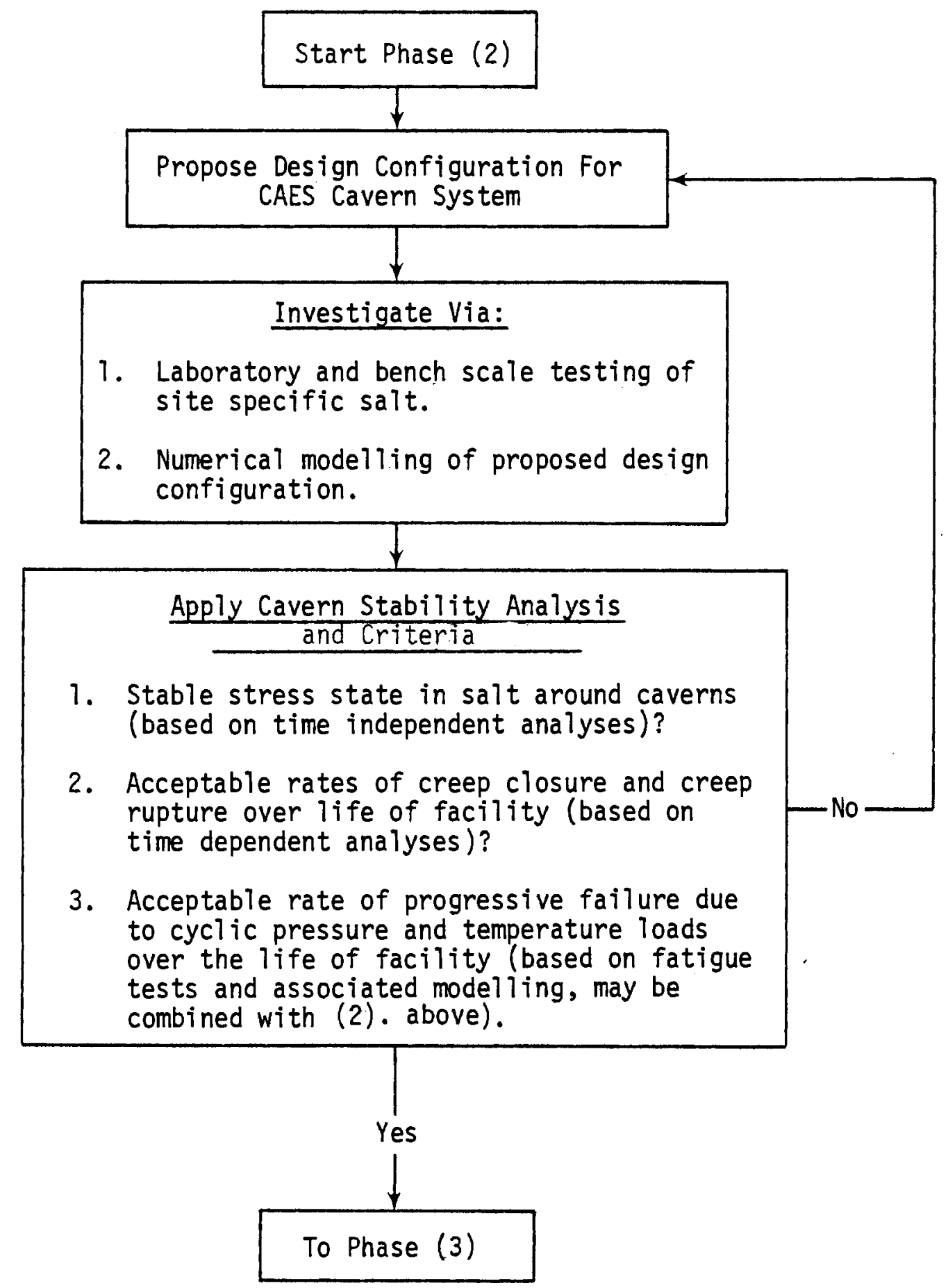

Fig. 6.4-2. Phase (2): Implementation of Stability Criteria In Cavern System Design 


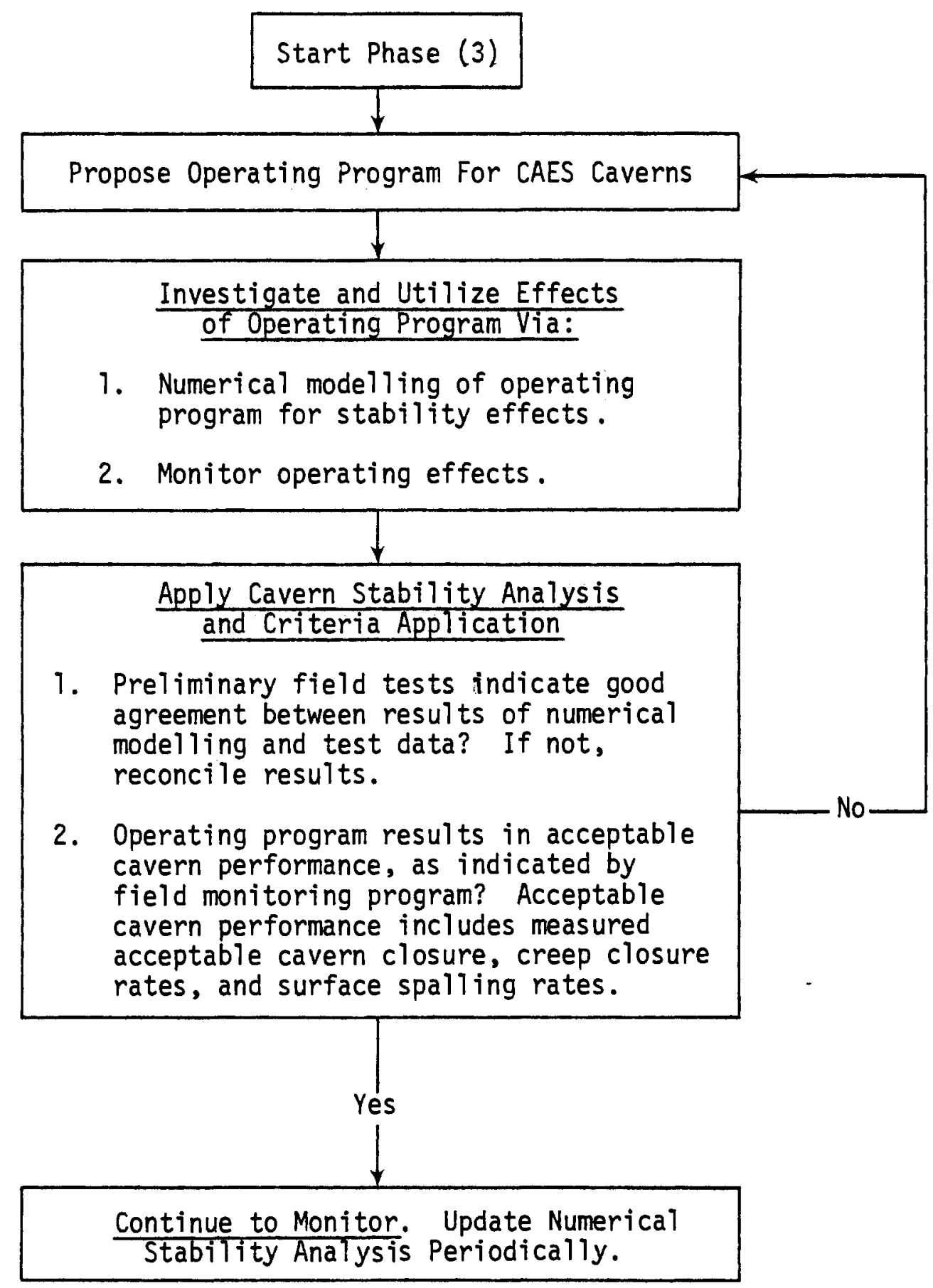

Fig. 6.4-3. Phase (3): Implementation of Stability Criteria For Operating Program. 


\section{COMPARISON OF NONCOMPENSATED AND COMPENSATED CAES CAVERNS}

\subsection{General}

Basically two types of caverns appear feasible for CAES air reservoirs in salt domes, i.e., (1) The noncompensated, or "constant" volume cavern, and (2) The compensated, or "constant" pressure cavern. Noncompensated caverns, which are the type discussed for the most part in this report, consist essentially of a "dry" opening in salt. A sufficient volume of compressed air must be maintained to furnish an adequate flow within limits of pressure over the time interval of powerpeaking generation. The required air flow and pressure magnitudes are based on a combination of the anticipated power demand load, the characteristics of the surface facilities of the CAES plant, and the limits set by the site-specific stability criteria for the air reservoir caverns.

Compensated caverns are maintained at "constant" pressure by a water (saturated brine for salt) "leg" to the ground surface. The pressure within the cavern does not attain the amplitudes exhibited by noncompensated caverns, however this system is complicated by additional reservoir(s) and conduits to handle the compensating liquid. Smalier volume CAES reservoirs are required because a "cushion" of air is not required to maintain the pressure within limits over the interval of power generation (86).

\subsection{Relative Effects On Cavern Stability}

Table 7.2-1 summarizes relative effects on cavern stability for compensated versus noncompensated CAES caverns. 
$\underline{\text { Topic }}$

- Erosion-Dissolution

- Champagne Effect

- Pressure Magnitude

- Cyclic Loadings

- Volume of Caverns

- Complications of Construction
Noncompensated

Not Applicable

Not Applicable

More Flexibility

Possibly Negative

Larger Volume Required

Few
Compensated

Possibly Negative

Possibly Negative

Limited

Decreased Effect

Smaller Volume

Possibly More

Table 7.2-1. Relative Effects for Compensated versus Noncompensated CAES Caverns in Salt Domes.

- Erosion-dissolution due to the cyclic flow of the compensating brine in a compensated cavern and associated conduits and/or reservoir could possibiy be a negative effect. If the brine is not always completely saturated the long-term effects on highly soluble rock salt surrounding openings could be destructive. Degree of brine saturation is not very sensitive to pressure and temperature variations; but, the frequent and long-term cycling associated with CAES could cause cumulative effects of significance.

- The Champagne effect for compensated caverns refers to the phenomenon wherein the reservoir of compressed air "lifts", i.e., "airlifts" in "slugs", the brine leg (86). This is due to an unstable buoyancy effect created by air coming out of solution as the brine is subjected to decreasing pressure. The final stage, in principle, could cause a rapid depressurization of the CAES cavern. This in turn could cause a severe roof fall or other brittle-fracture effect within the walls of the salt of the cavern, as noted previously. 
- The pressure magnitude wi thin noncompensated caverns can be controlled; however, compensated caverns are restricted to pressures consistent with the brine "head" to the ground surface. Pressures within noncompensated caverns therefore could be increased to correspond more nearly with geostatic pressure levels, provided a maximum value, e.g., $0.9 \times$ depth $(f t)$ in psi $(6.9 \mathrm{kPa})$, was not exceeded. Decreasing the pressure difference (between geostatic and cavern pressure) should increase cavern stability.

- Cyclic loading effects have been discussed previously, and as noted, constitute a major unknown factor in long-term stability of CAES caverns in salt domes. The amplitudes of cyclic pressure and temperature loadings obviously will be larger for noncompensated, as contrasted to compensated, caverns. Thus the associated long-term stability effects could be more severe for noncompensated caverns. - Volume of caverns will be larger for noncompensated caverns; and thus, the volume of salt affected by the state of stress (as indicated by a nonlinear plasticity analysis) will be more extensive. Alternately, a number of caverns can be constructed to avoid possible negative effects associated with very large openings in rock salt. Provided an adequate volume of salt is present, there should be no difficulty with constructing a number of caverns for a CAES air reservoir system.

- Complications of construction will generally be of greater magnitude for compensated caverns. This may not directly affect longterm cavern stability; however the probability of stability related 
concerns could increase. For example, well casings, check valves, reservoir connections, etc. would increase in number; and thereby, possibilities would also increase for events affecting long-term cavern stability, e.g., brine induced corrosion of metal components. 


\section{CONCLUSIONS}

\subsection{Summary}

The results of a state-of-the-art review have been presented along with preliminary and general long-term stability criteria for CAES caverns in salt domes. Since long-term effects of cyclic loadings on rock salt are essentially unknown, it was not possible to specify quantitative criteria. However, a methodology has been outlined for developing site-specific and quantitative criteria. In addition, an implementation plan has been included for utilization of CAES stability criteria.

\subsection{Concluding Remarks}

CAES technology, relative to long-term stability of air reservoir caverns in salt domes and salt anticlines, currently is in an early stage of investigation. Much work remains to be done, particularly in relating site-specific field results to results predicted from engineering analyses based upon test data and numerical methods.

Adequate numerical programs and testing methods exist in principle to perform stability analyses of CAES caverns. At this time a substantial data base should be developed specific to environments anticipated for rock salt surrounding CAES caverns in domes and/or anticlines. Verification of one or more competing methods of analysis also should be completed as expeditiously as possible, with verification based on site-specific field results. 


\section{REFERENCES}

1. Abel, J. F., Rock Mechanics - Can It Pay Its Way? Third Symposium On Salt, Northern Ohio Geol. Soc., V. 2, 1970, P. 197-207.

2. Albrecht, H., and Langer, M., The Rheological Behavior of Rock Salt and Related Stability Problems of Storage Caverns, Advances In Rock Mechanics, Proc. of the Third Congress of the International Society for Rock Mechanics, V. II-B, 1974, p.967.

3. Albrecht, H., Meister, Stork, and Wallner, On the Problems of Establishing Proof of the Stability of Cavities in Salt Rocks, Vth International Symposium on Salt, Hamburg, May 29 - June 1, 1978, Proc. (to be published).

4. Allen, K., Eminence Dome - Natural Gas Storage In Salt Comes of Age, Journal of Petroleum Technology, Nov., 1972, p. 1299-1301.

5. Allen, R. V., Wood, D. M., and Mortensen, C. E., Some Instruments and Techniques for Measurements of Tidal Tilt, Phil. Trans. Roy. Soc. Lond. A., V. 274, 1973, p. 219-222.

6. Anonymous, Off-Peak Air Storage for Peaking Gas Turbines, Electrical World, Jan. 15, 1951, p. 64-65.

7. Atwater, G. I., and Forman, M. J., Nature and Growth of Southern Louisiana Salt Domes and Its Effect on Petroleum Accumulation. Am. Assoc. Pet. Geols. Bull., V. 43, 1959, p. 2592-2622.

8. Baar, C. A., Applied Salt-Rock Mechanics, Elsevier, New York, 1977.

9. Belchic, H. C., The Winnfield Salt Dome, Winn Parish, Louisiana, Guide Book, 1960 Spring Field Trip, Shreveport Geol. Soc., 1960.

10. Blecher, W. A., Giramonti, A. J., and Smith, E. B., An Analytical Treatment of the Champagne Effect Associated with Hydraulically Compensated Compressed Air Energy Storage Systems, 1978 Compressed Air Energy Storage Symposium, Pacific Grove, California, May 15-18, 1978, Proc. (to be published).

11. Boresi, A. P., and Deere, D. U., Creep Closure of a Spherical Cavity in an Infinite Medium (with Special Application to Project Dribble, Tatum Salt Dome, Mississippi), for: Holmes and Narver, Inc., May, 1963.

12. Bradshaw, R. L., Lomenick, T. F., McClain, W. C., Empson, F. M., et al., Model and Underground Studies of the Influence of Stress, Temperature and Radiation on Flow and Stability in Rock Salt Mines, Proc. First Congress of Inter. Soc. of Rock Mechanics, Lisbon, 11, 1966.

13. Busch, B., Etwas uber die Expainsivkraft des Salzes: Glukauf, v. 15, 1907 , p. 369-371. 
14. Busch, J. B. (Principal Investigator), Economic and Technical Feasibility Study of Compressed Air Storage, ERDA - 76-76, General Electric Company, Schenectady, New York, 12301, 1976.

15. Clark, S. P., Jr., Handbook of Physical Constants, The Geol. Soc. of Amer., Mem. 97, $196 \overline{6}$.

16. Cruden, D. M., The Form of the Creep Law for Rock Under Uniaxial Compression, Int. J. Rock Mechs. Min. Sci., V. 8, No. 2, Pergammon Press, 1971, p. 105-126.

17. Deere, D. V., Subsidence Due to Mining - A Case History from the Gulf Coast Region of Texas, Proc. Fourth Symposium on Rock Mechanics, March, 1961, Mineral Industries Experiment Station, Bu11. No. 76, The Pennsylvania State University, Nov., 1961, p. 59-64.

18. Desai, C. S., Nonlinear Analysis Using Spline Functions, Proc. ASCE, Jour. Soil Mechanics and Foundation Design, V. 97, SM 10, 0ct., 1971 .

19. Desai, C. S., and Abel, J. F., Introduction to the Finite Element Method, Van Nostrand Reinhold Co., New York, 1972, p. 215-244.

20. Dreyer, W. E., The Science of Rock Mechanics, Trans Tech Publications $1,1972$.

21. Dreyer, W. E., Results of Recent Studies on the Stability of Crude 0 il and Gas Storage in Salt Caverns, Proc. 4th International Symp. on Salt, V. II, Northern Ohio Geol. Soc., 1974, p. 65-92.

22. Dwyer, M. G., and Thoms, R. L., Finite Element Analysis of Salt Domes With Stored Hot Wastes, Fourth Symposium on Salt, Coogan, A. H., Ed., V. II, Northern Ohio Geol. Soc., 1974, p. 343.

23. Fossum, A., Visco-Plastic Behavior During the Excavation Phase of a Salt Cavity, Inter. Jour. for Numerical and Analytical Methods in Geomechanics, V. 1, 1977, p. 45-55.

24. Fossum, A. F., Callahan, G. D., and Hansen, F. D., Storage Room Structural Analysis For Radioactive Waste Isolation In Rock, Storage In Excavated Rock Caverns, (Rockstore 77), Proc. of the First International Symposium, Bergman, M., Ed., V. 3, Pergammon Press, 1977, p. 789 .

25. Giramonti, A. J., Preliminary Feasibility Evaluation of Compressed Air Storage Power Systems, Vols. I, II, R76-952 161-5, United Technologies Research Center, East Hartford, Conn. 06108, 1976.

26. Goodman, B. E., Van, T. K., and Henze, F. W., The Measurement of Rock Deformability in Boreholes, Proc. 10th U.S. Symposium on Rock Mechanics, The University of Texas, Austin, 1968. 
27. Guido, R. S., and Warner, S. E., Project Cowboy - Physical Properties of Salt Samples, Lawrence Radiation Laboratory, UCRL-6069, July, 1960.

28. Halbouty, M. T., Salt Domes - Gulf Region, United States and Mexico, Gulf Publishing Co., Houston, Texas, 1967, $425 \mathrm{p}$.

29. Handin, J., Strength and Ductility, Handbook of Physical Constants, Clark, S. P., Jr., Ed., The Geol. Soc. of Amer., Mem. 97, 1966, p. 223-289.

30. Handy, R. L., Pitt, J. M., Engle, L., and Klockow, D. E., Rock Borehole Shear Test, Proc. 17th U.S. Symposium on Rock Mechanics, Utah Engineering Experiment Station, University of Utah, Salt Lake City, Utah 84112,1976 , p. 4B6-1 to 11.

31. Hanna, M. A., Fracture Porosity In Gulf Coast, Amer. Assoc. Pet. Geols., Bul1., V. 37, No. 2, Feb., 1953, p. 266-281.

32. Hansen, F. D., Evaluation of An Inelastic Law For Salt Creep, Energy Resources and Excavation, Proc. 18th U.S. Symposium on Rock Mechanics, Wang, F. D., and Clark, G. B., Eds., Colorado School of Mines Press, 1977, pp. 4B5-1-5.

33. Hardy, H. R., Application of Microseismic Techniques to Monitoring of Storage Cavern Stability, (Rockstore 77 - Ibid), p. 321.

34. Hardy, H. R., Jr., Dimenșional Stability of Solution Mined Cavities in Salt, Proc. Symp. on Salt Dome Utilization and Environmental Considerations, Martinez, J. D., and Thoms, R. L., Eds., Louisiana State Univ. Press, 1977, p. 267-293.

35. Hardy, H. R., Jr., and Chugh, Y. P., Failure of Geologic Materials Under Low-Cycle Fatigue, Sixth Canadian Symposium on Rock Mechanics, Ecole Polytechnique, Montreal, May, 1970.

36. Hawkins, M. E., and Jirik, C. J., Salt Domes in Texas, Louisiana, Mississippi, Aiabama, and Offshore Tidelands: A Survey, U.S. Bureau of Mines Information Circular 8313, 1966.

37. Heard, H. C., Steady State Flow In Polycrystalline Halite at Pressure of 2 Kilobars, Geophysical Monograph Series Vol. 16, Flow and Fracture of Rocks, American Geophysical Union, p. 191-209, 1972.

38. Howells, D. A., Effects of Pressure and Temperature Change in A Compressed Air Storage Cavern, (Rockstore 77 - Ibid), p. 481.

39. Hoy, R. B., Foose, R. M., and O'Neill, Jr., B. J., Structure of Winnfield Salt Dome, Winn Parish, Louisiana, Amer. Assoc. Pet. Geols., Bull., V. 46, No. 8, Aug. 1962, P. 1444-1459.

40. Huggett, G. R., Slater, L. E., and Pavlis, G., Precision Leveling With A Two-Fluid Tiltmeter, Geophysical Research Letters, Vol. 3, No. 12, Dec. 1976. 
41. Jirik, C. J., and Weaver, L. K., A Survey of Salt Deposits and Salt Caverns, Their Relevance to the Strategic Petroleum Reserve, Report FEA/S-76/310, Federal Energy Administration, 1976.

42. Johnson, K. S., and Gonzales, S., Salt Deposits on the United States and Regional Geologic Characteristics Important for Storage of Radioactive Waste, Report Y/OWI/Sub-7414/1, Earth Resources Assocs., Inc., Athens, Georgia, March, 1978.

43. King, M. S. and Acar, K. Z., Creep Properties of Saskatchewan Potash As a Function of Changes on Temperature and Stress, Third Symposium On Salt, Rau, T. L., and Dellwig, L. F., Eds., V. 2, Northern Ohio Geological Society, 1970, p. 226-235.

44. Kupfer, D. H., Shear Zones Inside Gulf Coast Salt Stocks Help to Delineate Spines of Movement, Amer. Assoc. Pet. Geols., Bu11., V. 60, 1976, p. 1434-1447.

45. Kupfer, D. H., Problems Associated with Anomalous Zones in Louisiana Salt Stocks, U.S.A., Vth International Symposium on Salt, Hamburg, West Germany, May 1978 (to be published).

46. Langhaar, H. L., Energy Methods In Applied Mechanics, John Wiley and Sons, 1962, p. 2 .

47. LeCompte, 'P., Creep in Rock Salt, Jour. of Geology 73, May, 1965, p. $469-484$.

48. Lomenick, T. F., Accelerated Deformation of Rock Salt at Elevated Temperature and Pressure and Its Implications for High Level Radioactive Waste Disposal, Ph.D. Dissertation, University of Tennessee, March, 1968.

49. Martinez, J. D., Technology of Gulf Coast Sait, Proc. Symp. on the Geology and Technology of Gulf Coast Salt, Kupfer, D. H., Ed., School of Geoscience, Louisiana State University, Sept., 1970, p. 149-159.

50. Martinez, J. D., (Principal Investigator), An Investigation of the Utility of Gulf Coast Salt Domes for the Storage or Disposal of Radioactive Wastes, Report ORNL Sub-4112-25, Institute for Environmental Studies, Louisiana State University, 1976, Also, Report Y/OWI/Sub-4112-37 (Same Title, 1977).

51. Mattick, W., Weber, 0., Stys. Z. S., and Haddenhorst, H. G., HuntorfThe World's First 290 MW Gas Turbine Air Storage Peaking Plant, Proc. Amer. Power Conf., Illinois Institute of Technology, Chicago, 111., Apri1, 1975.

52. Maxwe 11, Wahi, Reaugh, Hofmann, A Time-Dependent Creep Model for Salt, Vth Internation Symposium On Salt - Ibid.

53. McClain, W. C., A Study of the Strata Movement in the Partial Extraction of Potash, Ph.D. Thesis, University of Newcastle, 1964. 
54. Menard, L., Measures in situ des proprietes physiques des sols, Annales des Ponts et Chaussees, no. 3, 1957, p. 357-377. (This device later was extended to rock and frequently is referred to as a "pressure meter" or "pressure cell").

55. Murray, G. E., Geology of the Atlantic and Gulf Coastal Province of North America, Harper and Bros., New York, 1962, 692 P.

56. Nair, K., Sandu, R. S., and Wilson, E. L., Time-Dependent Analysis of Underground Cavities Under Arbitrary Initial Stress Field, Proc. 10th U.S. Symposium on Rock Mechanics, Austin, Texas, 1968.

57. Nair, K., and Singh, R. D., Creep Rupture Criteria for Salt, Fourth International Symposium on Salt, Northern Ohio Geological Society, 1974 , p. $41-49$.

58. Nair, K., and Deere, D. U., Creep Behavior of Salt in Triaxial Extension Tests, Third Symposium on Salt, Northern Ohio Geol. Soc., V. 2, 1970, P. 208-215.

59. Nolte, Wierczeyko, Problems Occurring During the Sonar Logging of Storage Caverns, Vth International Symposium on Salt - Ibid.

60. Obert, L., and Duva 11, W. I., Rock Mechanics and the Design of Structures in Rock, John Wiley and Sons, Inc., 1967, p. 409.

61. Obert, L., In Situ Determination of Stress in Rock, Mining Engineer, Aug., 1962, p. 51-58.

62. Obert, L., Deformation Behavior of Model Pillars Made From Salt, Trona, and Potash Ore, Proc. Sixth Symp. on Rock Mechanics, Rolla, MO, 1964 , p. 339-560.

63, Ode, H.,"Review of Mechanical Properties of Salt Relating to Salt Dome Genesis", Diapirism and Diapirs, Mem. 8, The American Assoc. of Pet. Geols., 1968.

64. Pariseau, W. G. , Thermoelastic/PLastic Analysis in Rock Mechanics, Numerical Methods in Geomechanics, V. 2, Desai, C. S., Ed., ASCE, 1976, p. 1768-1187.

65. Potts, Horseman, Thompson, An Investigation Into Underground Gas Storage in Brine Well Cavities, Vth International Symposium on Salt - Ibid.

66. Project Dribble Petrographic Examination and Physical Tests of Cores, Tatum Salt Dome, Mississippi, U.S. Army Waterways Experiment Station, Corps of Engineers, Vicksburg, Mississippi, Tech. Report No. 6-614, Jan., 1963.

67. Reyes, S. F., and Deere, D. U., Elasto-plastic Analys is of Underground Openings by the Finite Element Method, Proc. First Congress of Inter. Soc. of Rock Mechanics, 11, Lisbon, 1966, p. 477-486. 
68. Rohr, H. U., Mechanical Behavior of a Gas Storage Cavern in Evaporitic Rock, Proc. 4th International Symposium on Sait, V. II, Northern Ohio Geol. Soc., 1974, p. 93-100.

69, Rokahr, R., Lux, K., and Lorenzen, H., Possibilities for the Assessment of the Stability of Salt Caverns, Vth International Symposium on Salt - Ibid.

70. Russel1, J. E., A Creep Model for Salt, Vth International Symposium on Salt - Ibid; also, Report Y/OWI/TM-32, Office of Waste Isolation, Oak Ridge, Tennessee, May, 1978.

71. Salt Domes of South Louisiana, New Orleans Geological Survey, Stipe, J. C., and Raymond, J. P., Eds. (1960, 1963), Vols. I, II, New Orleans, LA., 1963.

72. Serata, S., Utilization of Stress Envelopes in Design of Solution Cavities, Fourth Symposium on Salt, Coogan, Ed., V. 2, The Northern Ohio Geological Society, 1974, p. 51.

73. Serata, S., Borehole Stress - Property Measuring System, U.S. Patent No. 3, 796, 091 , March 12, 1976.

74. Serata, S., Prerequisites for Application of Finite Element Method to Solution Cavities and Conventional Mines, Third Symp. on Salt, Northern Ohio Geol. Soc., V. 2, 1970, p. 249-279.

75. State of Louisiana, Statewide Order No. 29-M, "rules and regulations pertaining to the use of salt dome cavities for storage of liquid and/or gaseous hydrocarbons, etc.", Department of Conservation, Baton Rouge, July, 1977.

76. Stottlemyre, J. A., and Smith, G. C., Stability Criteria for Compressed Air Energy Storage in a Porous Rock Reservoir, 1978, CAES Symposium - Ibid.

77. Strategic Petroleum Reserve, Final Environmental Impact Statement for Bayou Choctaw Salt Dome, Federal Energy Administration, FES 76-5, Dec., 1975.

78. Stys, F. S., Peaking Power from Stored Air, Civil Engineering, ASCE, Jan., 1977, p. 48-51.

79. Terzaghi, K., From Theory to Practice in Soil Mechanics, John Wiley and Sons, New York, 1960.

80. Thoms, R. L., Char, C. V., and Bergeron, W. J., Finite Element Analysis of Creep in Rock Salt Pillar Models, New Horizons in Rock Mechs., Proc. Fourteenth Symp. on Rock Mechs., ASCE, 1973, p. 393-408. 
81. Thoms, R. L., Eidemiller, R. I., and Hilding, R. K., A Preliminary Survey of Seismic Velocities Through In-Situ Rock Salt, Petroleum Division of American Society of Mechanical Engineers, Energy and Technology Conference and Exhibition, Houston, Texas, Nov. 5-9, 1978.

82. Thoms, R. L., and Manning, T. A., Monitoring Salt Dome Movement, Proc. Inter. Conf. on Finite Element Methods in Engr., Cheung, Y. K. and Hutton, S. G., Eds., Univ. of Adelaide, Australia, Dec., 1976.

83. Thoms, R. L., Manning, T. A., Paille, L. K., Gehle, R. M., Site Specific Study for Possible Ongoing Salt Dome Movement, Proc. 18th U.S.Symp. on Rock Mechanics, Colorado School of Mines, June, 1977.

84. Thoms, R. L., and Martinez, J. D., Blowouts in Domal Salt, Vth Inter. Symp. on Salt, Hamburg, W. Germany, May-June, 1978. (to be published).

85. Triaxial Compression Tests of Salt Rock Cores for the United States Atomic Energy Commission - Project Dribble, United States Department of the Interior, Bureau of Reclamation, Laboratory Report No. C-1043, Oct. 29, 1962, Clearinghouse TID-21592.

86. Vosburg, G. H., (Principal Investigator), Conceptual Design for a Pilot/Demonstration Compressed Air Storage Facility Employing a Solution-Mined Salt Cavern, EPRI EM-391, Electric Power Research Institute, 3412 Hillview Ave., Palo Alto, Calif. 94304, 1977.

87. Wallace, W. E., Fault and Salt Map of South Louisiana, Trans Gulf Coast Assoc. Geol. Societies, V. 14, 1966, p. 373.

88. Wawersik, W. R., Callendar, J. F., Weaver, B., and Dropek, R. K., Preliminary Determination of Mechanical Properties of Rock Salt From Southeastern New Mexico, Site Characterization, Proc. 17 U.S. Symposium On Rock Mechanics, Utah Engineering Experiment Station, 1976 , p. 5C6-1-7.

89. Wawersik, Hannum, Mechanical Behavior of New Mexico Rock Salt in Triaxial Compression Up To $200^{\circ} \mathrm{C}$., Vth International Symposium on Salt, Hamburg, Proc. (to be published), May 29-June 1, 1978.

90. Whitehouse, G. D., Council, M. E., Martinez, J. D., Peaking Power With Stored Air, Power Engineering, Jan. 1968, p. 50-52,

91. Winkel, B. V., Gerstle, K. H., and Ko, H. Y., Analysis of TimeDependent Deformations of Openings in Salt Media, Int. J. Rock. Mech. Min. Sci., V. 9, 1972, p. 249-260.

92. Wittke, W., Pierau, B., and Schetelig, K., Planning Of a CompressedAir Pumped-Storage Scheme At Vianden/Luxembourg, (Rockstore 77Ibid), P. 367.

93. Zienkiewicz, 0. C., The Finite Element Method, Third Edition, McGraw Hi11, London, T977. 